NASA Technical Memorandum 107214

AIAA-96-1745

\title{
Baseline Acoustic Levels of the NASA Active Noise Control Fan Rig
}

\author{
Daniel L. Sutliff \\ Lewis Research Center \\ Cleveland, Ohio \\ M. Nallasamy \\ NYMA, Inc. \\ Brook Park, Ohio \\ Laurence J. Heidelberg and David M. Elliott \\ Lewis Research Center \\ Cleveland, Ohio
}

Prepared for the

Second Aeroacoustics Conference

cosponsored by the American Institute of Aeronautics and Astronautics and the Confederation of European Aerospace Societies

State College, Pennsylvania, May 6-8, 1996

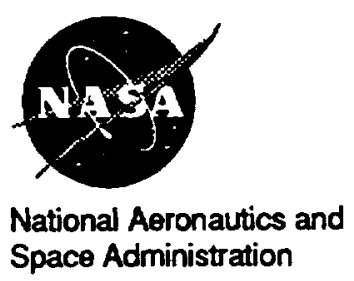




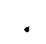


BASELINE ACOUSTIC LEVELS OF THE NASA ACTIVE NOISE CONTROL FAN RIG

\author{
Daniel L. Sutliff $\ddagger$ \\ NASA Lewis Research Center \\ Cleveland, Ohio 44135 \\ M. Nallasamy $\ddagger$ \\ NYMA, Inc. \\ Brookpark, Ohio 44142 \\ Laurence J. Heidelberg $\ddagger$ \\ NASA Lewis Research Center \\ Cleveland, Ohio 44135 \\ David M. Elliott \\ NASA Lewis Research Center \\ Cleveland, Ohio 44135
}

\begin{abstract}
Extensive measurements of the spinning acoustic mode structure in the NASA 48" Active Noise Control Fan (ANCF) test rig have been taken. A continuously rotating microphone rake system with a least-squares data reduction technique was employed to measure these modes in the inlet and exhaust. Farfield directivity patterns in an anechoic environment were also measured at matched corrected rotor speeds. Several vane counts and spacings were tested over a range of rotor speeds. The Eversman finite element radiation code was run with the measured in-duct modes as input and the computed farfield results were compared to the experimentally measured directivity pattern.
\end{abstract}

The experimental data show that inlet spinning mode measurements can be made very accurately. Exhaust mode measurements may have wake interference, but the least-squares reduction does a good job of rejecting the nonacoustic pressure. The Eversman radiation code accurately extrapolates the farfield levels and directivity pattern when all in-duct modes are included.

\section{INTRODUCTION}

Theoretical and experimental 1 work have shown that Active Noise Control (ANC) can significantly reduce the tone levels of ducted fans. Without adequate knowledge of the physical structure of the acoustics, computational ANC studies can over simplify and lead to overly optimistic conclusions. A full scale engine test of a new ANC concept currently is a high risk. To bridge this gap, the NASA Lewis Research Center's Active Noise Control Fan serves as a test bed to verify proposed ANC technologies. The ANCF can also be used for Computational Aeroacoustic (CAA) code verification.

A unique characteristic of turbomachinery noise is the modal structure. The acoustic waveform is three-dimensional and highly complex, and is best described as a spinning mode. Knowledge of these spinning modes is important to identify the generation mechanism and to successfully apply noise control.

This paper provides the baseline acoustic noise measurements of the ANCF. In-duct mode levels and corresponding farfield tonal and broadband directivity patterns are presented and compared to radiation computer code results.

\section{ACTIVE NOISE CONTROL EAN RIG}

The ANCF, shown in figures 1 and 2 (described more fully in a companion paper $^{2}$ ), as configured for these experiments, has a 16bladed rotor at $40^{\circ}$ pitch in a 48 inch diameter duct. The inlet duct relative length is one diameter. The entrance is a cylindrical duct, followed by a spinner. The spinner is a $1: 1.5$ ellipsoid starting just upstream of the rotor

$\dagger$ This work was performed while the author held an NRC-NASA LeRC Research Associateship.

$\ddagger$ Senior Member, AIAA 
plane. This spinner transitions the duct to a hub-to-tip ratio, $\sigma$, of 0.30 at the rotor plane. The exhaust duct relative length is also one diameter with a hub-to-tip ratio of 0.30 just down stream of the rotor converging to 0.5 at the duct exit plane.

The fan rotor consists of 16 commercially available ventilation blades. These have an average chord length of 4.5".

The stator vane chord is 4.5 " stacked on the mid-chord line, with a $12^{\circ}$ twist. The tip section is a modified 65-(12)10 airfoil and the hub a 65-(18)10 airfoil. The airfoil camber was modified to account for cascade effects and the trailing edge slightly rounded off. This design results in a very nearly axial flow aft of the stators. Stator vane counts of 13,14,26, and 28 were tested. The stators are identical, resulting in varying solidity ratios. Nominal spacing between the rotor trailing edge and the stator leading edge varied: $1 / 2,1.0$, and 2.0 times the chord length (c) of 4.5" (i.e., 2.25", 4.5" and 9.0"). This spacing is measured at the hub from the fan blade trailing edge to the stator blade leading edge.

The fan rotational speed varied from 1100 to 1886 corrected speeds (revolutions-perminute RPM $\left(\Omega_{c}\right)$ ). This gives a blade passing frequency (BPF) of 290 to $500 \mathrm{~Hz}$ resulting in a wide range of cut-off ratios depending upon the mode being analyzed. The second and third harmonics, 2BPF and 3BPF, are also obtained.

The ANCF is located in the Aeroacoustic Propulsion Facility3 (AAPL) at NASA Lewis, a hemispherical anechoic (to $125 \mathrm{~Hz}$.), test facility to allow farfield noise measurements. Farfield measurements are taken from 28 microphones at approximately 50 feet in the ANCF horizontal plane. The distance to the microphones varies since the ANCF is not in the exact center of the facility. The Sound Pressure Level (SPL) data are corrected to $40 \mathrm{ft}$, standard day conditions. The farfield tonal and broadband directivity plots are obtained from these microphones. The bandwidth is $2.2 \mathrm{~Hz}$.

\section{FAN/DUCT MODES}

\section{THEORY}

The classic paper by Tyler and Sofrin 4 presents the theory of fan-duct mode generation and propagation. The generation of circumferential spinning modes is governed by the following equation:

$$
\mathbf{m}=\mathbf{s B}+/-\mathbf{k V}
$$

where

$$
\begin{aligned}
& m=\text { circumferential mode number } \\
& \mathbf{s}=\text { harmonic index } \\
& \mathrm{B}=\text { number of rotor blades, } \\
& \mathrm{k}=\text { an integer }(0,1,2, \ldots), \\
& \mathrm{V}=\text { number of stator vanes. }
\end{aligned}
$$

The rotor locked mode $(k=0, m=s B)$ spins at the shaft rotation speed. This mode, and higher order modes, can only propagate in a narrow annular duct if the blade tip speed corresponding to its spin rate is above $\mathrm{Mach}=$ 1.0. Lower order modes, which spin faster, may propagate if their spin rate results in a sonic blade tip speed. The critical tip mach number is greater than 1.0 for non-narrow annular ducts. The spin rate of a circumferential mode is determined by the following equation:

$$
\begin{aligned}
& \boldsymbol{\Omega}_{\mathrm{m}}=s B \Omega / \mathrm{m} \\
& \boldsymbol{\Omega}_{\mathrm{m}}=\text { mode rotation speed, } \\
& \boldsymbol{\Omega}=\text { shaft rotation speed }
\end{aligned}
$$

Each circumferential mode, $\mathrm{m}$, can have one or more radial modes, $n$. Mode propagation is dependent on the cut-off frequency, which is unique to each $(m, n)$ mode. This frequency is dependent on geometric parameters and the eigenvalue of a combined Bessel function which is a solution to the cylindrical wave equation. Below the cut-off frequency the mode will decay exponentially. Above cut-off propagation occurs and acoustic power is transmitted down the duct and into the farfield. The cut-off frequency is given by:

$$
f_{c o}=\hat{e}_{c_{0}} / \pi D
$$

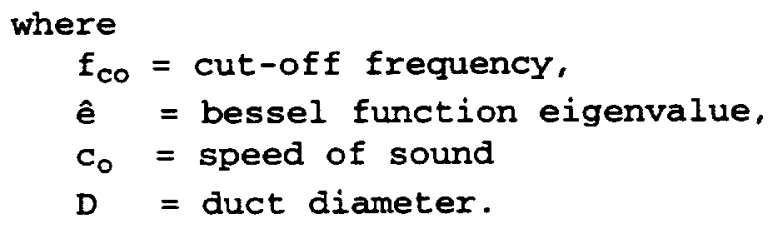

The bessel function eigenvalue incorporates the duct geometry effects. The cutoff ratio gives the ratio of the mode frequency to its cut-off frequency.

$$
\zeta=f / f_{c o}=\pi s B\left(\Omega_{I n}\right) D / 60 \hat{e ̂ c}
$$


One method of generation of these spinning modes is the periodic interaction of the rotor wake impinging on the stator vanes. These are the primary modes of interest in the ANCF. A second method of generation is caused by change in rotor blade loading due to aerodynamic disturbances upstream of the rotor. If these disturbances are periodic with respect to the rotor, spinning modes may be generated. An example of this type of disturbance deliberately created in the ANCF is upstream rods 2 . Other discontinuities in the duct wall can generate unwanted modes as did the segmented casing treatment in the Advanced Ducted Propulsor 5 . These modes, while generally undesirable, can contain significant acoustic levels.

The modes generated by rotor/stator interaction can be predicted using equations 1-3 for the vane counts used in this study. The cut on modes and their cut-off ratios at $\Omega_{c}=1886$ are presented in table I.

\section{TABLE Ia: Cut-on Modes at $\Omega_{c}=1886$}

\begin{tabular}{|c|c|c|c|}
\hline HARMONIC : & BPF & \multicolumn{2}{|l|}{ 2BPF } \\
\hline \multicolumn{4}{|l|}{ VANE COUNT } \\
\hline 13 & $(3,0)$ & \multicolumn{2}{|c|}{$(6,0),(-7,0)$} \\
\hline 14 & $(2,0)$ & \multicolumn{2}{|l|}{$(4,0),(4,1)$} \\
\hline 26 & --- & \multicolumn{2}{|l|}{$(6,0)$} \\
\hline 28 & --- & \multicolumn{2}{|l|}{$(4,0),(4,1)$} \\
\hline \multicolumn{4}{|c|}{ TABLE Ib: Cut-off Ratios $\Omega_{c}=1886$} \\
\hline & \multirow{2}{*}{$\begin{array}{l}\text { INLET } \\
(\sigma=0.0)\end{array}$} & \multicolumn{2}{|c|}{ EXHAUST } \\
\hline & & $(\sigma=0.35)$ & $(\sigma=0.5)$ \\
\hline \multicolumn{4}{|l|}{ BPF MODES } \\
\hline$(2,0)$ & 1.85 & 1.94 & 2.11 \\
\hline$(3,0)$ & 1.35 & 1.36 & 1.43 \\
\hline \multicolumn{4}{|l|}{ 2BPF MODES } \\
\hline$(4,0)$ & 2.13 & 2.13 & 2.13 \\
\hline$(4,1)$ & 1.22 & 1.26 & 1.28 \\
\hline$(6,0)$ & 1.51 & 1.51 & 1.52 \\
\hline$(-7,0)$ & 1.32 & 1.32 & 1.32 \\
\hline
\end{tabular}

\section{MEASUREMENTS}

A rake consisting of 6 acoustic microphones spaced at approximately equal radial intervals is used to measure the modes. The inlet mode measurements are taken near the inlet entrance where the hub to tip ratio is 0.0 . The exhaust measurements were taken just upstream of the converging section of the duct, or alternatively, the exit plane. At those locations the hub-to-tip ratios are 0.35 and 0.5 , respectively. Therefore, separate, removable rakes are used in the inlet and exhaust to measure the radial profile efficiently. The rotating rake apparatus can be moved upstream or downstream of these locations by rearranging the spool order. These locations are shown on the ANCF schematic, figure 2.

The rake assembly rotates about the duct center line at $1 / 100$ th of the fan shaft rotation speed. This induces a doppler shift in the acoustic spinning modes generated by the fan. Recognizing that each circumferential mode spins at a unique multiple of the shaft rotation, narrow band frequency analysis is used to obtain the mode levels. The circumferential mode profiles are separated into radial modes through a least-squares curve fit using Bessel functions to match the experimental data. Details of the rotating rake data collection and analysis techniques are presented in references [2] and [6].

A sample of the reduced data is tabulated in table 3. The header includes the rig configuration information and the mode $(m, n)$ for which the particular case was curve fit. The pressure magnitude (Pascals) and phase (degrees) is listed versus microphone normalized radial location. The computed pressures are determined from the least-squares-fit of the radial Bessel functions to the actual pressure profile. A vector error is determined at each radial location from the difference between the actual and computed complex pressures divided by the maximum experimental pressure. The overall error of the solution is defined as the average of the radial vector errors.

Inner wall, outer wall, mode pressure and power levels are calculated from the decomposed modal data. $\mathrm{C}_{\mathrm{mn}}$ is a normalizing coefficient, similar to that used by the V0727 code. The function multiplier is the coefficient of the Bessel function. The Sofrin coefficient is defined as the maximum pressure along radial profile. The Power Level (PWL)is calculated, including cut-off ratio and Mach number effects, and summed to obtain the total mode power level. It was found that for an individual mode, about 85 to $90 \mathrm{~dB}$ PWL is the minimum level measurable with the setup described herein. 


\section{RESULTS AND DISCUSSION}

A baseline which can be used for ANC parametric design or code verification has been created by testing several vane counts at 3 different vane spacings. The data were resolved into BPF, $2 \times B P F$, and $3 \times B P F$ harmonics. However the $3 \times B$ BP levels were generally not significantly above the noise floor and are not reported. Table II shows the configurations tested.

\section{TABLE II: ANCF Configurations Tested} ( ID $=$ In-Duct,$F F=$ Farfield)

$\begin{array}{cccc}\text { VANE SPACING: } & 1 / 2 \mathrm{C} & 1 \mathrm{C} & 2 \mathrm{C} \\ \text { VANE COUNT } & & & \\ 13 & \text { ID } & & \\ 14 & \text { ID } / F F & \text { ID } / F F & \text { ID } / F F \\ 26 & \text { ID/FF } & \text { ID/FF } & \\ 28 & \text { ID } / F F & \text { ID } / F F & \end{array}$

The accuracy of least-square modal curve fit is an indication of the confidence in the solution. The accuracy is defined as the average vector error between the experimental and calculated bessel function fitted pressures referenced to the maximum pressure. (see Avg 'Vector Err $=\mathrm{x} \cdot \mathrm{xx} \%$ ' on figure 3 ). The radial curve fit solutions for the inlet are exceptional, usually less than 5\% error. However, the exhaust solutions are generally not as good, with errors of $10 \%$ to $20 \%$. This indicates contamination of some kind. The solution can be mathematically improved by using higher order, cut-off radials in the fit. This improvement is not dramatic, and is contrary to physical acoustics. Another possibility is acoustic reflections. Results of interior acoustic computer codes show this hypothesis may be valid for limited modes. A third possibility is interference with the hydrodynamic wake. Ongoing studies are investigating these possibilities.

\section{IN-DUCT MODAL ANALYSIS}

When all significant circumferential components, a complete modal structure can be presented in 3-D bar graph form. The circumferential mode index, $\mathrm{m}$, is plotted on the $x$-axis and the radial mode index, $n$, on the $y$ axis. The mode power level in each $(m, n)$ mode is given by the bar on the z-axis. The total mode power level in each circumferential mode is along the back wall of the 3-D plot. Finally, the power in each circumferential mode is summed to obtain the total tone power, $\mathrm{PWL}_{\text {tor }}$. Power is chosen as the parameter to present because of its relationship to farfield propagation. Theory and experimental data show that near cut-on the mode SPL becomes very high (theoretically infinite at cut-off) but does not contribute to farfield noise. The RPM at which the rotor-stator interaction mode is strongest is presented in this paper to best illustrate the characteristics of the fan.

Figure 4a shows the inlet modal structure for 13 vanes, spaced at $1 / 2 c, \Omega_{c}=1800$. The level of the expected rotor/stator generated mode at BPF $(3,0)$ in the inlet is $112.1 \mathrm{~dB}$ PWL. The next highest mode is $(4,0)$ at $95.9 \mathrm{~dB}$. The total power is $112.3 \mathrm{~dB}$. Almost all of the power generated by the fan at this condition is due to the rotor/stator interaction. Another way of defining this which is relevant to ANC is to sum the power in only the non rotor/stator interaction modes, in this case, $99.0 \mathrm{~dB}$. Thus a noise control floor of (112.1 - 99.0) 13.1 dB would represent the maximum noise reduction possible if a ANC system were to completely eliminate $\mathrm{m}$ $=3$. Some caution must be exercised in using this computation, since the modes not shown may exist just below the measurement floor of approximately $85 \mathrm{~dB}$. Were several of these to exist, the floor could, in reality be higher.

The $(3,0)$ mode is stronger in the exhaust (figure 4b) at $116.4 \mathrm{~dB}$ PWL. The extraneous modes levels are similar to those noted in the inlet. An overall mode penetration of $17.7 \mathrm{~dB}$ exists. This illustrates a common occurrence in fan modal analysis, of modes neighboring a strong interaction mode being weakly excited.

Thirteen vanes generate the $(6,0)$ and $(-$ $7,0)$ modes at 2BPF. These modes are seen in figures $4 c \& 4 d$.

An additional mode exists at $2 \mathrm{BPF}, \mathrm{m}=$ -1 . The first three radials $(n=0,1,2)$ are cut-on at this low order mode. These are attributed to the Inflow Control Device (ICD), which has 11 ribs $(32-3 \times 11=-1)$. These ribs cause flow distortions with which the fan interacts. This mode is generally insignificant compared to the rotor-stator interaction mode, except in a few isolated cases.

For 14 vanes $\left(1 / 2 c, \Omega_{c}=1886\right)$ the BPF rotor-stator interaction mode is $(2,0)$. Figures $5 \mathrm{a}$ $\& 5 b$ show this mode is clearly dominant. The 
extraneous modes are at very low levels resulting in a very clean mode structure. The mode penetration levels are 20.0 and $21.3 \mathrm{~dB}$ in the inlet and exhaust, respectively.

Figures $5 \mathrm{c} \& 5 \mathrm{~d}$ show the same condition at $2 \mathrm{BPF}$ where the interaction mode is $m=4$. At this frequency 2 radials are cut-on, $(4,0) \&(4,1)$. The $(4,1)$ mode dominates. In the exhaust the $m=-1$ ICD mode is actually higher than the rotor stator mode, which can cause problems when trying to demonstrate noise control.

The rotor-stator interaction at BPF is cutoff for 26 and 28 vanes. The 26 vane count has a single cut-on interaction mode $(6,0)$ at $2 \mathrm{BPF}$ (figure 6). Twenty-eight vanes (figure 7) produce $(4,0) \&(4,1)$, the same modes as for 14 vanes. Cutting-off BPF resulted in a 3-6 dB higher PWL at 2BPF in both of these vane configurations. The inlet noise at $2 \mathrm{BPF}$ is 109.1 $\mathrm{dB}$ for 28 vanes. The sum of BPF and $2 \mathrm{BPF}$ PWLs in the inlet for 14 vanes is $110.2 \mathrm{~dB}$. Cutting-off BPF in this limited case did not result in substantially reduced noise.

Examination of figures 4-7 show that this fan is aft noise dominated at BPF and at 2BPF it is inlet dominated.

\section{INTERACTION MODES VS RPM}

The PWL of the interaction modes are plotted vs. $\Omega_{c}$ for 13 vanes at a single $1 / 2$ chord $(1 / 2 c)$ spacing on figure 8 . Figures $8 \mathrm{a}$ and $8 \mathrm{~b}$ show the variation in $(3,0)$ in the inlet and exhaust at BPF. The speed at which the mode cuts-on is noted on the graph. At 2BPF (figures $8 \mathrm{c}$ and $8 \mathrm{~d}$ ) an interesting relationship between $\Omega_{c}$ and mode PWL is seen. A general rise in PWL with increasing $\Omega_{c}$ is seen until $1800 \Omega_{c}$, at which point a drastic reduction in the level occurs. This shape occurs in both modes $(6,0)$ and $(-7,0)$ and in the inlet and the exhaust at nearly the same frequency. These modes have different axial wavelengths. Thus, since the distance between the acoustic source (the vanes) and the measurement location is different in the exhaust and inlet, and the axial wavelength of the two modes is different, this reduction is unlikely due to reflection. Further analysis of this trends and discussion follows.

Figure 9 shows the effect of rotor-stator spacing on the PWLs generated by 14 vanes. In general, as the spacing increases PWL decreases because the wake decays with axial distance.
The levels as a function of $\boldsymbol{\Omega}_{\mathrm{c}}$ tend to increase with increasing $\Omega_{c}$ especially in the exhaust. The total power in mode 4 at $2 B P F$ is shown in $9 \mathrm{c}$ and $9 \mathrm{~d}$ for all spacings. The PWLs vary as expected in the inlet. There is a slight indication of the PWL reduction at $1886 \Omega_{c}$ exhaust.

Figure 10 breaks mode 4 into its radial components. The $(4,0)$ is cut-on over the entire range tested. The $(4,1)$ cuts on at $\Omega_{c}=1544$ in the inlet and 1496 in the exhaust. This fan clearly is dominated by the higher radial when it is present. In the inlet, at $1886 \Omega_{c}$, the $(4,1)$ is about $12 \mathrm{~dB}$ higher than $(4,0)$.

The $(6,0)$ mode generated by 26 vanes (figure 11) shows a similar functional characteristic vs RPM as when generated by 13 vanes (refer back to figure 8). A finer RPM increment was taken to investigate this phenomenon in more detail. The drop off in mode power is substantial, a $20 \mathrm{~dB}$ drop over a 136 RPM increase in the inlet. Farfield directivities confirm this.

The levels are up to $6 \mathrm{~dB}$ lower in the exhaust, but the dramatic PWL drop at $1886 \Omega_{c}$ still exists. In addition, this drop off also occurs when the spacing is increased to one chord length, in both directions. In fact, very little PWL difference due to chord spacing is noted in the inlet.

The reason for this characteristic in PWL vs RPM is unknown. The fact that this phenomenon occurs at so many different physical conditions indicates that it may arise from a change at the source. Ongoing studies are investigating the possible influence of the tip vortex which may leave the blade at a different angle than the rotor wake.

The total power at $2 B P F$ in the $m=4$ interaction mode for 28 vanes is shown in figure 12. The exhaust data conforms to the interesting trend. The inlet data has a more familiar trend; the power increases with increasing RPM. The exhaust shows a mild falloff in PWL, similar to the 14 vane case. Figure 13 shows the individual cut-on radials $(4,0)$ \& $(4,1)$ independently. The breakdown into the radial components shows that the interference is occurring in the $n=1$ radial.

To investigate the nature of the modal solution in the aft duct, data were taken with the rake mounted in two locations. The initial location was mid-duct, between the 2 nd and 3 rd 
aft spool pieces (see figure 2). Note that this is just at the point were the duct annulus starts to converge. An alternative location is the exhaust exit plane. Previous experiments ${ }^{2}$ with different inlet rake locations showed no qualitative or quantitative difference in the modal solution.

Figure 14 shows the effect of aft measurement location. The pressure profiles at these locations are quite different due to the change in hub-to-tip ratio, which influences the bessel functions. The $(2,0)$ mode at BPF shows about a $3 \mathrm{~dB}$ difference between the measurement locations. This could be due to reflection caused by the convergence. Figures $14 \mathrm{~b}-\mathrm{d}$ indicate that at $2 \mathrm{BPF}$, modes $(4,0)$ \& $(4,1)$, the PWL at each station is generally within one $\mathrm{dB}$, indicating that it is unlikely a significant reflection exists at this mode.

\section{FARFIELD ANALYSIS}

The farfield SPL for 14 vanes, three chord spacings is shown in figure 15 . The tone and the broadband directivity are shown for BPF \& 2BPF. The lobes from the dominant $m=2$ inlet and exhaust modes are seen at $30^{\circ}$ and $136^{\circ}$ in figure $15 \mathrm{a}$. At these modal peaks the difference in SPL levels between the different chord spacings compare favorably to the induct levels. For example, in the farfield exhaust lobe, a $13 \mathrm{~dB}$ SPL level difference is noted between the $1 / 2 \& 1$ chord spacings. An $11 \mathrm{~dB}$ PWL difference was noted in-duct. The aft domination of the noise is propagated to the farfield. Figure $15 \mathrm{~b}$ confirms the inlet dominance of the noise at $2 \mathrm{BPF}$.

Figure 16 presents the farfield data for 26 vanes. The insignificant difference in PWL due to chord spacing that was seen in-duct is also seen in the farfield, particularly in the inlet. The lobe at $40^{\circ}$ is due to the $(6,0)$ inlet mode. The smaller lobe at $5^{\circ}$ is from the $(-1, n)$ modes. The exhaust directivity also shows the $m=6$ lobe and what appears to be interference from the $\mathbf{m}=-1$ lobe. Modes of different circumferential order can combine in unique ways depending on their relative phasing creating constructive and destructive interference in the directivity patterns, making it difficult to attribute the farfield directivity characteristics at a single azimuthal angle to specific modes.

The 28 vane farfield directivity on figure 17 confirms the relative levels of the in-duct modal distribution has been propagated to the farfield. The $(4,1)$ mode is $9 \mathrm{~dB}$ higher in the inlet and $1 \mathrm{~dB}$ higher in the exhaust (figure 7).
The $(4,1)$, having a cut-off ratio closer to unity has a greater farfield propagation angle when measured from the axis. The $(4,0)$ lobe angles are at approximately $22^{\circ}$ and $142^{\circ}$. The $(4,1)$ lobe angles are at approximately $45^{\circ}$ and $118^{\circ}$. The relative levels of these lobes compare favorably to the in-duct mode levels noted.

\section{RADIATION CODE VERIFICATION}

\section{COMPUTATION OF FAREIELD RADIATION}

\section{INLET RADIATION}

Eversman and Roy8 solve the noise radiation problem using a finite element method. The propagation in the duct and the radiation to the farfield are included in one model. The acoustic problem is formulated in terms of the acoustic perturbation velocity potential. They solve the duct eigenvalue problem for a duct with uniform flow. The formulation is a Bessel equation of order $m$. The finite element solution of this equation is the approximation to the exact solution. They employ a Galerkin type finite element formulation with isoparametric elements. The mean flow is computed using a velocity potential formulation on the same mesh that is used for acoustic propagation and radiation. The acoustic field equations are written in terms of the acoustic potential and acoustic pressure, and solved using finite element techniques.

The source is modeled in terms of the incident and reflected modes, which are matched to the finite element solution on the same plane. Wave envelope elements are used in the farfield, assuming that the sound field there approximates that produced by a point source. It is assumed that only outgoing waves exist at the farfield boundary, where a Sommerfeld radiation condition for a monopole in a uniform flow is applied. The same boundary conditions are applied at the baffle boundary8 . With the wave envelope elements in the farfield the entire radiation field can be modeled with a relatively small number of finite elements. The solution to the finite element system is obtained using a frontal solution method. Further details of the finite element formulation and the solution procedure may be found in reference 8 .

\section{AFT RADIATION}

The equations governing the acoustic field of the aft radiation are the same as those used for the inlet. However, the jet shear layer from the nozzle introduces a complication for the computation of the mean flow. The shear 
layer is modeled as though the duct is extended four duct radii beyond the exit plane9. The velocity potential is allowed to be discontinuous across the shear layer. The acoustic pressure is continuous over the entire region. Beyond this "extended" duct, the internal and external flows are allowed to mix and the velocity potential is continuous everywhere. The extent of the "extended" duct can be varied if needed.

The finite element techniques and computer codes developed by Eversman and Roy have been applied to modern turbofans 10,11 and NASA's active noise control fan ${ }^{12}$.

The present computations were done on Active Noise Control Fan geometry that was tested in the Aeroacoustic Propulsion Laboratory at Lewis Research Center. The farfield boundary is located at 10 diameters, where farfield measurements are made. A long center body and a flanged exit characterize the aft duct geometry. In this study the source (input) plane is the rotating rake measurement plane of the inlet or exhaust duct. The computation is carried out separately for the inlet and aft radiation as indicated above. The propagation through the inlet and aft ducts and the respective farfield radiation are studied. A composite prediction of the farfield directivity is computed from $0^{\circ}$ to $180^{\circ}$ by combining the inlet and aft radiation results. In the intermediate region where the radiation from the inlet and aft interfere with each other, the mean square pressures from the inlet and aft have been added to get the resultant curve11. The computed farfield directivities are compared with the measurements.

As explained earlier, exhaust modal data were taken with the rotating rake at two different axial locations in the aft duct. Figure 18 shows that there is no significant difference in the results of farfield propagation code when using the experimental data from these different locations. The results shown here and figure 14 indicates that the rotating rake system is measuring and computing the modal distribution very well.

\section{COMPARISONS TO EXPERIMENTAL}

\section{DATA}

Figure 19 overlays the results from the code on to the experimental data at BPF acquired for the 14 vane configuration (1886 $\left.\Omega_{c}, 1 / 2 \mathrm{c}\right)$. The lobe peak angle comparisons are excellent. The magnitude comparisons are also very good. There is a little plane wave contamination at $0^{\circ}$ to $10^{\circ}$ in the experimental data where no match is expected.

At $2 \mathrm{BPF}$, figure 20 , the two lobes of the two radial modes are seen. Naturally, the computer simulation shows the theoretical sharp separation, which the experimental data cannot show due to extraneous modes and not enough spatial resolution. Figure 20a shows the farfield experimental data compared to the code results run with a single mode, the $m=4$ interaction mode. The agreement in the aft quadrant is not very good. This is due to the presence of the $\mathrm{m}=-1$ mode. Referring back to figure $5 \mathrm{~d}, \mathrm{~m}=-1$ is stronger than $m=4$ mode. Therefore, it is not surprising that the agreement is not good. A substantial improvement is noted when $m=-1$ is included as shown on figure $20 \mathrm{~b}$.

Figure 21 shows the code experimental data comparisons for 26 vanes. The ICD mode at $10^{\circ} \& 155^{\circ}$ are not included in the computation, but are seen in the experimental data. Also, the constructive and destructive interference in the range $70^{\circ}$ to $110^{\circ}$ due to the overlap in the inlet and exhaust propagation fields do not agree,. This is expected because for these computations the code used the rms pressure to obtain the overlap between the inlet and exhaust fields. The inlet lobe peak angle is in good agreement. A slight over-protection in the magnitude is seen. The aft directivity does not agree due to the interference in the $m=-1$ mode.

The directivity comparison for 28 vanes is shown on figure 22 . The peak angles of the two lobes from the $(4,0) \&(4,1)$ modes are again predicted very well. The magnitude of the strong inlet mode levels are also in excellent agreement. The aft directivity agreement is not good because of the weaker exhaust mode levels, which also have several interfering modes $(\mathrm{m}=-$ $1,3 \& 5)$ of approximately equal amplitude (figure 7b). Again, this is an indication of the problems associated with modes combining in the farfield resulting in possible azimuthal variations in the directivity.

\section{CONCLUDING REMARKS}

The in-duct modal structures of the ANCF test rig were presented for 13, 14, 26 and 28 vanes spaced at $1 / 2,1$ and 2 chord lengths. The corresponding farfield directivity was also shown. The interaction mode as a function of rotor corrected RPM were presented in this paper. Complete modal structure at each RPM 
was also taken and exists as a database, but was not presented due to space constraints.

The modal structure shows the expected high levels at the rotor-stator interaction mode. At $2 \mathrm{BPF}$, the $\mathrm{m}=-1$ mode caused by the ICD exists. In a few cases, this mode may be higher than the mode caused by rotor-stator interaction. An ICD which does not generate a cut-on disturbance at $2 \mathrm{BPF}$ is being built. Also, the modal structure shows that modes neighboring a rotor-stator interaction are sometimes generated.

Both inlet and exhaust modes were measured. Excellent modal solutions were obtained in the inlet. The aft modal solutions were possibly contaminated by the wake. Current efforts are underway to examine this contamination and reduce its influence.

There is a unique characteristic in the mode interaction PWL level as a function of RPM. This couples very well to the 26 vane wake interaction, causing extreme destructive interference at $1886 \Omega_{\mathrm{c}}$. It is unknown what causes this. Ongoing studies are investigating the possible influence of the tip vortex which may leave the blade at a different angle than the rotor wake.

Comparisons of the experimental farfield directivity to CAA code predictions show good agreement when a single mode exists in the duct. If more than one mode exists in the duct, these must be included in the code input to obtain accurate directivity patterns. The directivity overlap between the inlet and exhaust from the code is not expected to be accurate since in the present computations the code uses rms pressure to obtain the overlap. This is not a limitation in the code, rather absolute phase was not available from the experimental data. The ANCF data acquisition process will be refined so that the mode absolute phase is obtained. With absolute phase, the CAA can preserve complex pressure in the farfield to better predict the directivity in the overlap region.

\section{REFERENCES}

[1] Sutliff, D.L., and Nagel, R.T.,"Active Control of Farfield Noise from a Ducted Propeller", AIAA Journal, Vol. 33, No. 2, February 1995, pp. 231-236.

[2] Heidelberg, L.H., Hall, D.G., Bridges, J.E., and Nallasamy, M., "Ducted Fan Test Bed for Active Noise Control and Aeroacoustics
Research", AIAA Paper 96-1740 May 1996, also NASA TM-107213, May 1996.

[3] Cooper, B.A., "A Large Hemi-Anechoic Chamber Enclosure for Community-Compatible Aeroacoustic Testing of Aircraft Propulsion Systems", Journal of the Institute of Noise Control Engineering of the USA, Jan/Feb 1994.

[4] Tyler, J.M., and Sofrin, T.G., "Axial Flow Compressor Studies", SAE Transactions, Vol. 70, 1962, pp. 309-332.

[5] Heidelberg, L.H., and Hall, D.G., "Inlet Acoustic Mode Measurements Using a Continuously Rotating Rake", Journal of Aircraft, Vol. 32, No. 4, July-August 1995, pp. 761-767.

[6] Hall, D.G., Heidelberg, L.H., and Konno, K., "Acoustic Mode Measurements in the Inlet of a Model Turbofan Using a Continuously Rotating Rake: Data Collection/Analysis Techniques", NASA TM-105936, January 1993; also AIAA paper 93-0599, January 1993.

[7] Meyer, H.D. and Envia, E., "Aeroacoustic Analysis of Turbofan Noise Generation", NASA CR-4715, March 1996.

[8] Eversman, W, and Roy, I.D., "Ducted Fan Acoustic Radiation Including the effects of Non-Uniform Mean Flow and Acoustic Treatment", AIAA 93-4424, 1993.

[9] Eversman, W, "Aft Fan Duct Acoustic Radiation", CEAS/AIAA 95-155, 1995.

[10] Philbrick D.A. and Topol, D.A., "Development of a Fan Noise Design System, Part 1: System Design and Source Modeling", AIAA 93-4415, 1993.

[11] Topol, D.A., "Development of a Fan Noise Design System, Part 2: Farfield Radiation and System Evaluation", AIAA 93-4416, 1993.

[12] Nallasamy, M., "Noise Radiation from Fan Inlet and Aft Ducts", AIAA Paper 96-1769, 1996. 


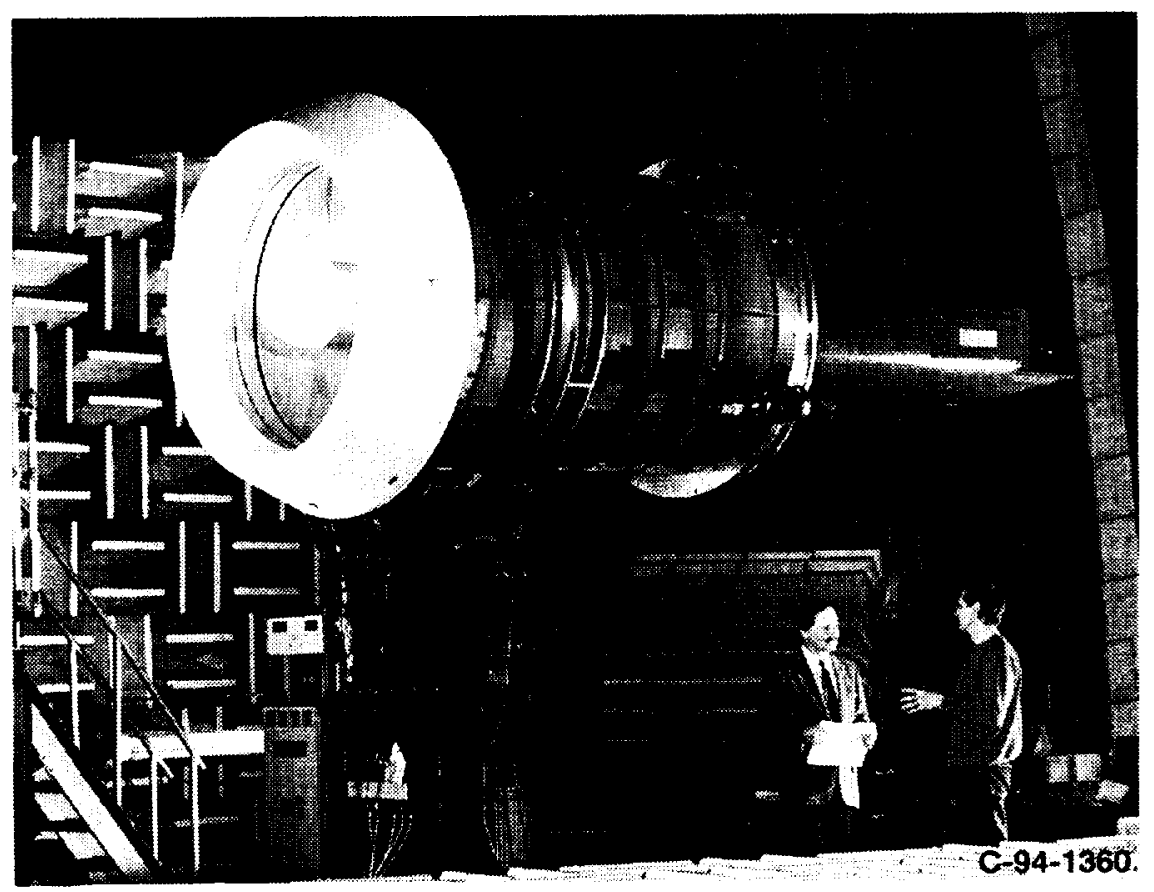

(a) ANCF with a bare inlet

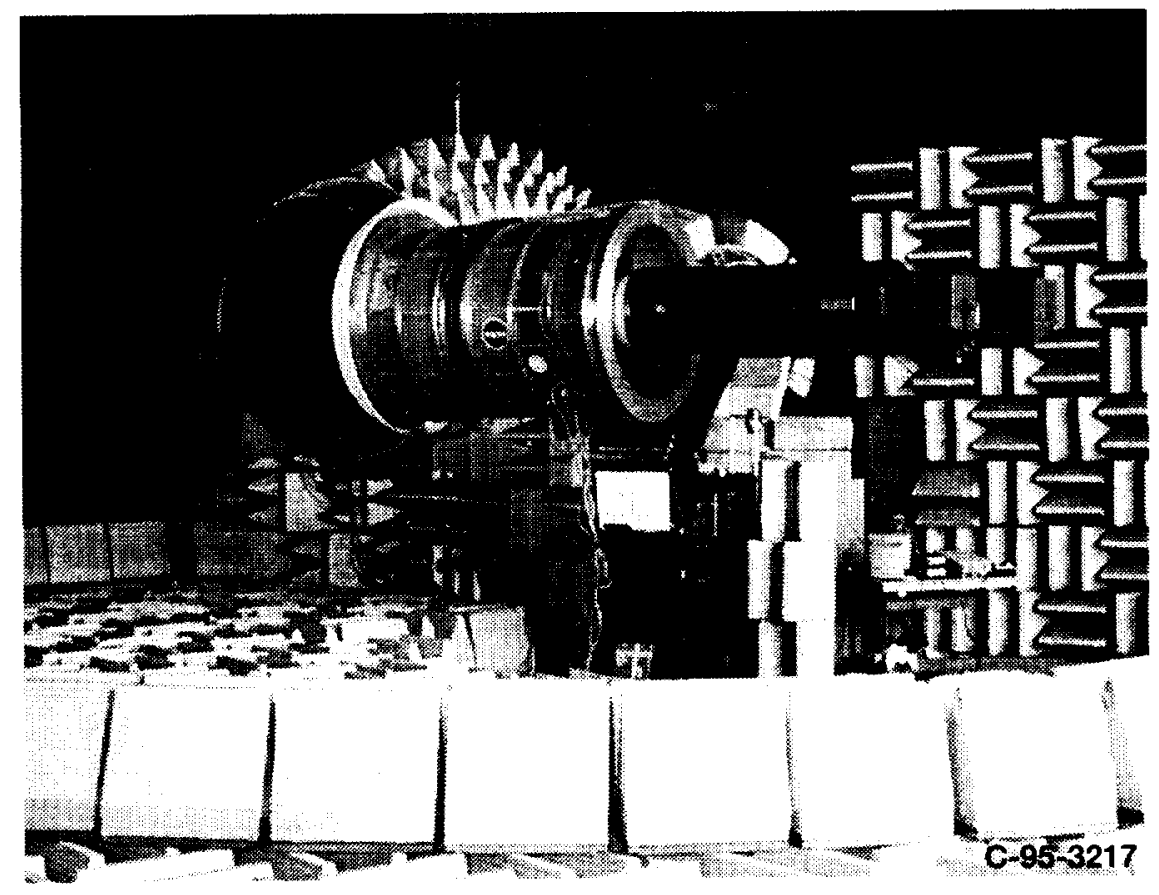

(b) ANCF in the far-field test position with the Inflow Control Device (ICD) installed

Figure 1. Active Noise Control Fan (ANCF) Test Rig. 


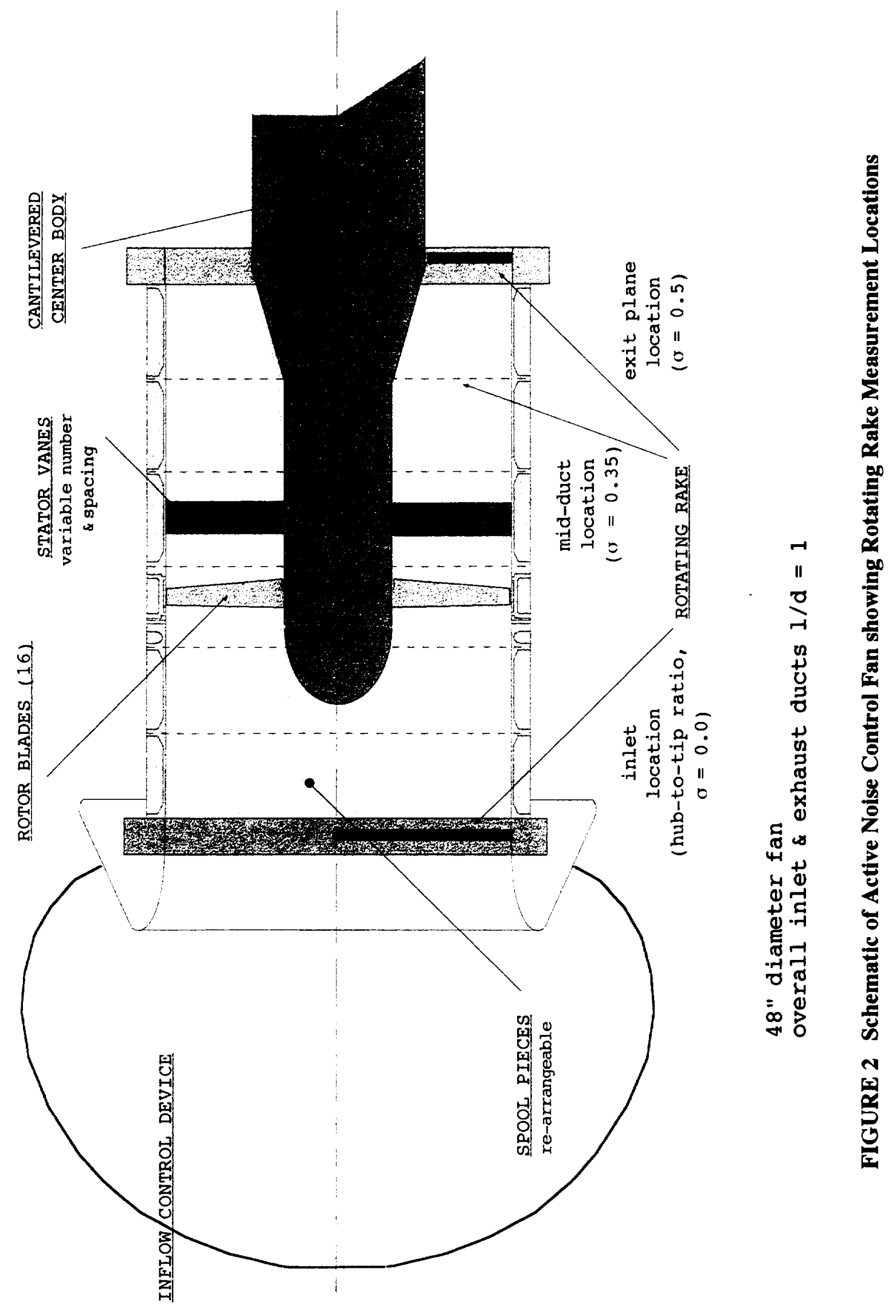




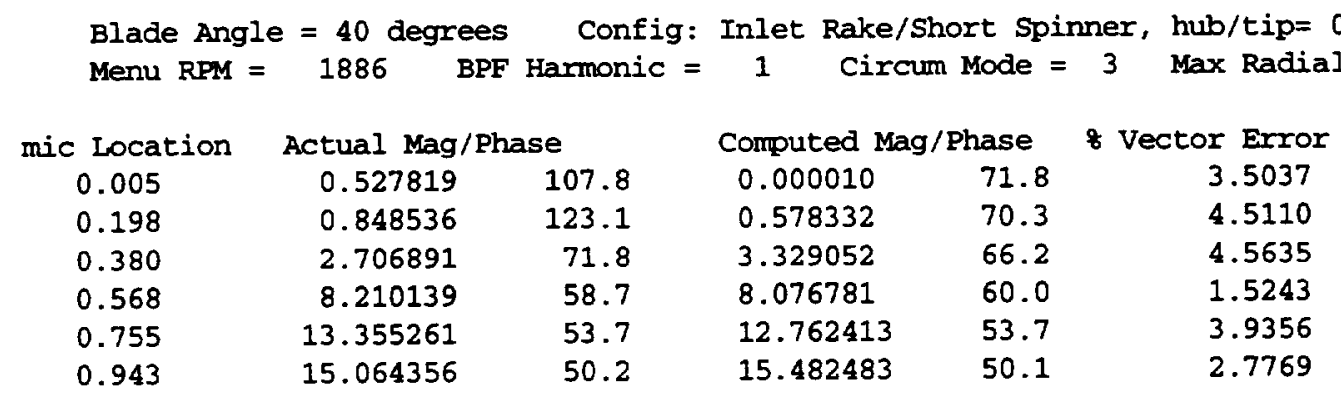

Avg Vector Err= 3.46918

Radial Coefficients (BBN Normalization)

\begin{tabular}{lrrrrrrr} 
n & \multicolumn{2}{c}{ C_mn Values } & \multicolumn{2}{c}{ Real/Imag } & \multicolumn{2}{c}{ Magnitude } & Phase \\
0 & 3.28837 & 0.00000 & 6.872 & 8.980 & $11.31(\mathrm{~Pa})$ & $115.0(\mathrm{~dB})$ & 52.6 \\
1 & 3.70374 & 0.00000 & -0.244 & 0.781 & $0.94(\mathrm{~Pa})$ & $92.3(\mathrm{~dB})$ & 107.4
\end{tabular}

\begin{tabular}{|c|c|c|c|c|c|c|c|c|c|}
\hline & $\begin{array}{l}\text { Func } \\
\text { (Pa) }\end{array}$ & $\begin{array}{l}\text { Mult } \\
\text { (dB) }\end{array}$ & $\begin{array}{l}\text { Sofrin } \\
\text { (Pa) }\end{array}$ & $\begin{array}{r}\text { Coeff } \\
\text { (dB) }\end{array}$ & $\begin{array}{l}\text { Inner } \\
\text { (Pa) }\end{array}$ & $\begin{array}{l}\text { Wall } \\
(\mathrm{dB})\end{array}$ & $\begin{array}{l}\text { Outer } \\
\text { (Pa) }\end{array}$ & $\begin{array}{l}\text { wall } \\
\text { (dB) }\end{array}$ & $\begin{array}{l}\text { Phase } \\
\text { (deg) }\end{array}$ \\
\hline & 37.18 & 125.4 & 16.15 & 118.5 & 0.00 & 0.0 & 16.15 & 118.5 & 52.6 \\
\hline & 3.04 & 103.7 & 1.31 & 96.4 & 0.00 & 0.0 & 0.88 & 92.9 & 107.4 \\
\hline
\end{tabular}

$\begin{array}{lcc}\text { n } & \text { Cut Ratio } & \text { Power }(\mathrm{dB}) \\ 0 & 1.35108 & 113.33 \\ 1 & 0.70817 & 0.00 \\ \text { Total } & \text { Power }= & 113.33 \text { (PWL dB) }\end{array}$

\section{a) Rake in Inlet}

Blade Angle $=40$ degrees Config: Exhaust Rake mid-duct, hub/tip $=0.3520$ Menu RPM $=1886$ BPF Harmonic $=1$ Circum Mode $=3$ Max Radial $=1$

\begin{tabular}{cccccc} 
mic Location & \multicolumn{2}{c}{ Actual Mag/Phase } & \multicolumn{2}{c}{ Computed Mag/Phase } & Vector Error \\
0.377 & 3.700426 & 153.4 & 2.765597 & 137.4 & 4.9322 \\
0.492 & 5.009575 & 156.0 & 4.988208 & 148.6 & 2.4666 \\
0.606 & 7.586354 & 157.6 & 9.777608 & 156.6 & 8.3785 \\
0.721 & 16.284429 & 146.6 & 16.051630 & 160.6 & 15.0730 \\
0.835 & 26.210045 & 170.3 & 21.977093 & 162.5 & 20.4369 \\
0.950 & 23.005103 & 161.0 & 25.506937 & 163.3 & 10.1880
\end{tabular}

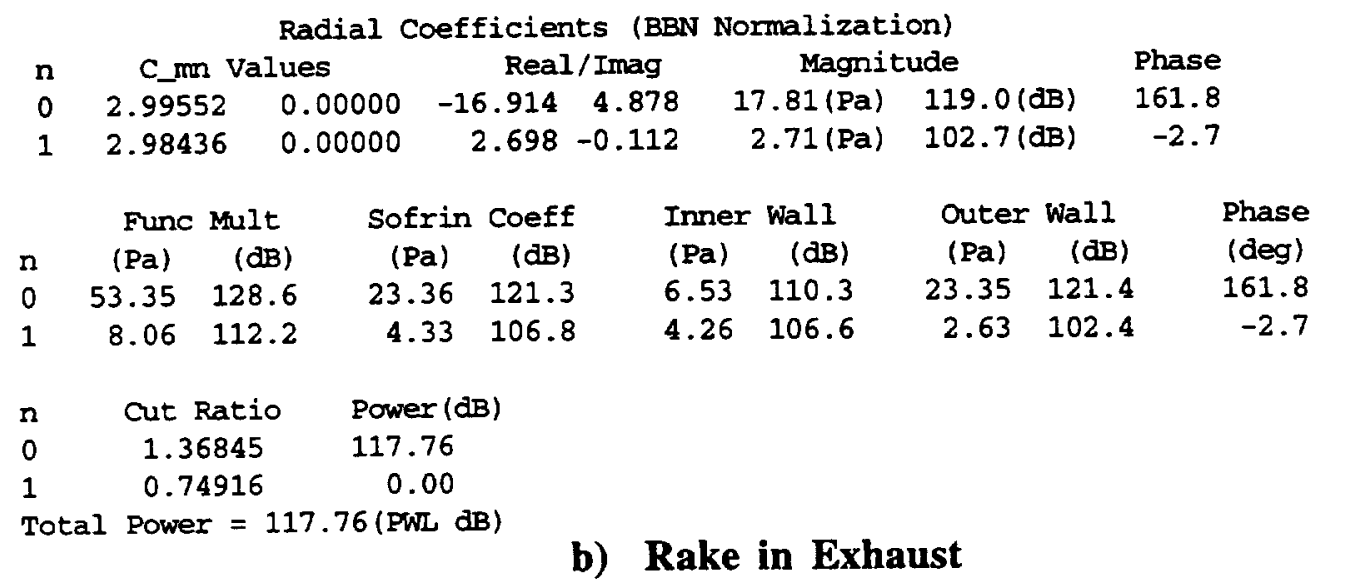

TABLE 3. Sample Data Reduction Output. 

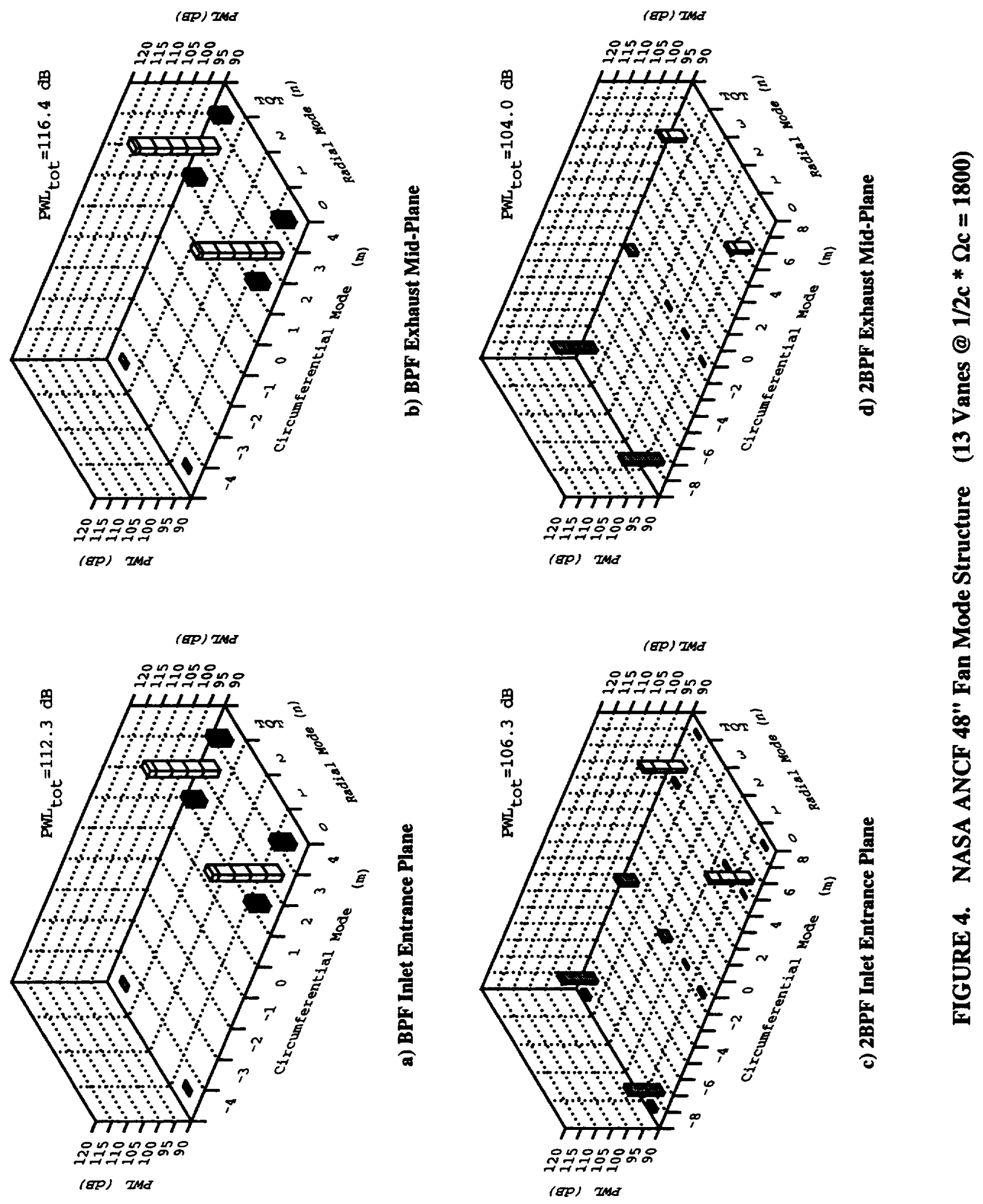

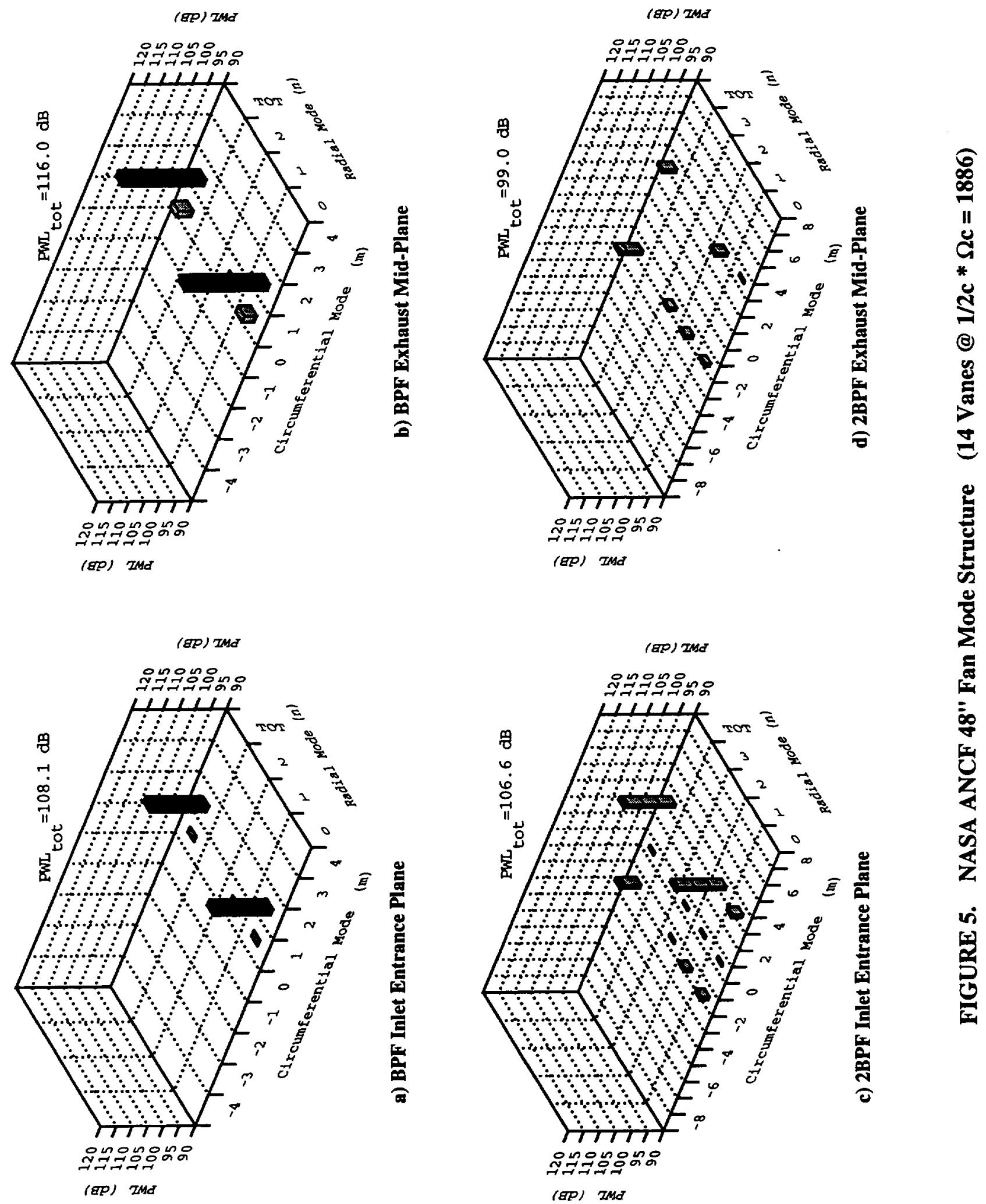

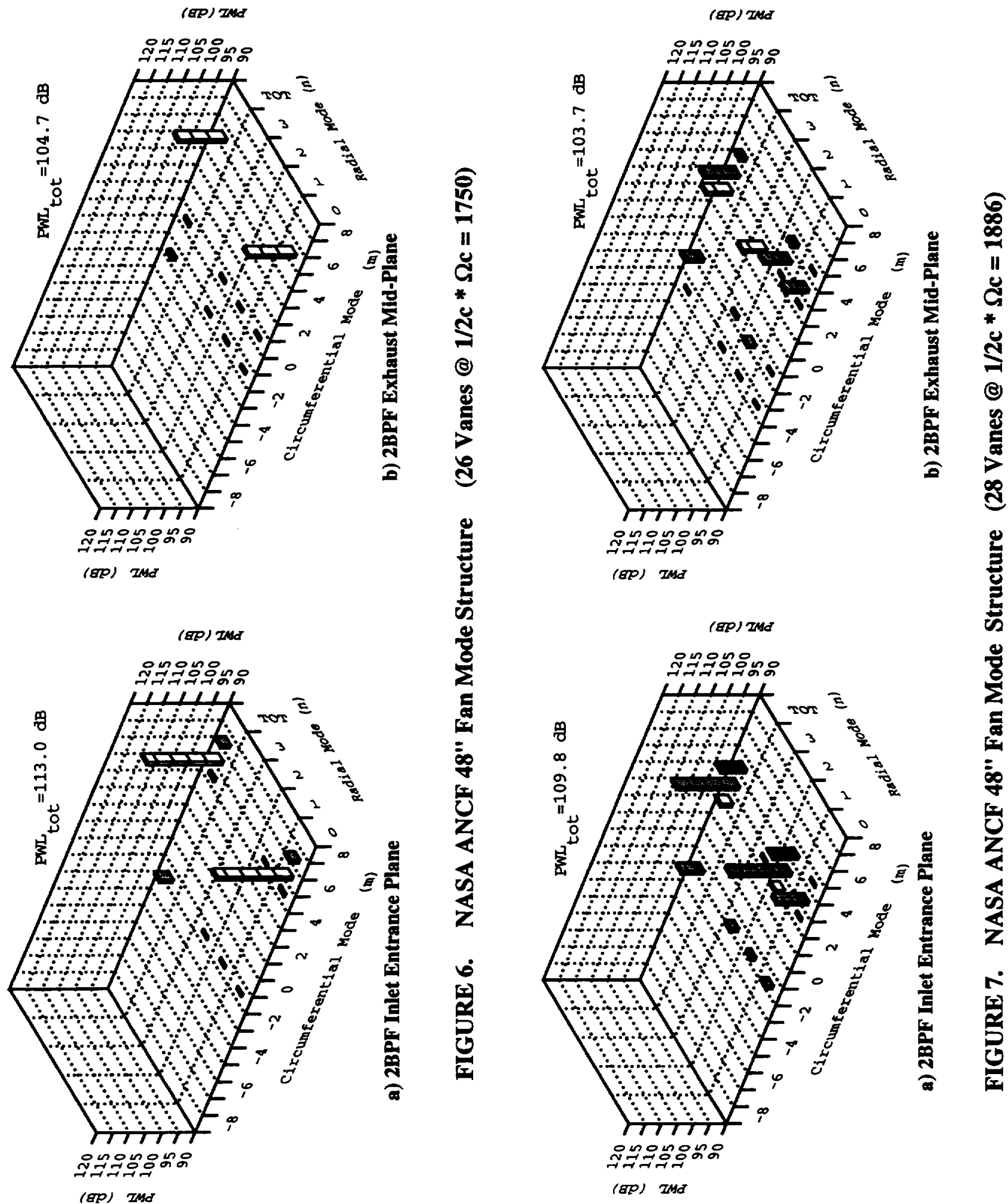

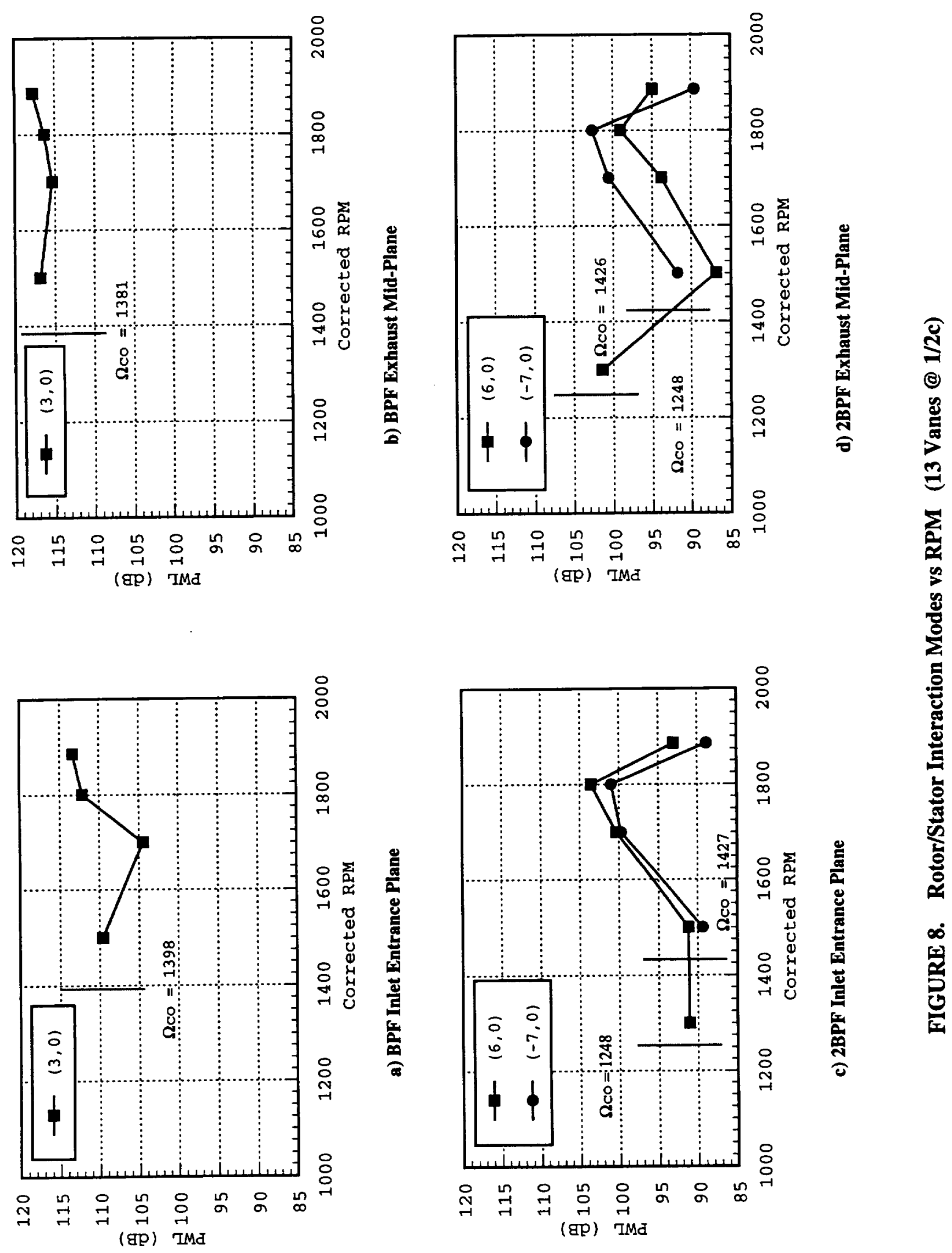

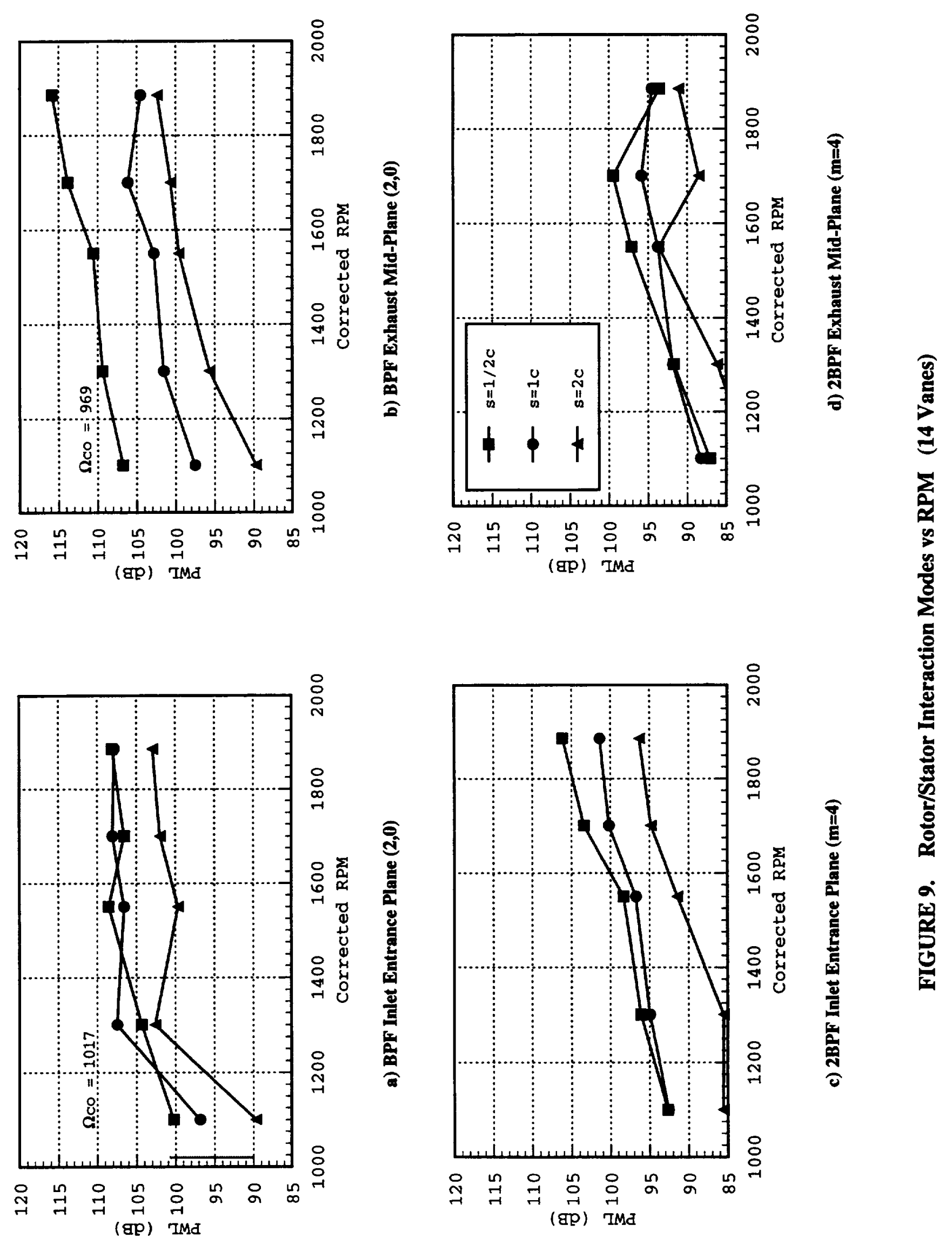

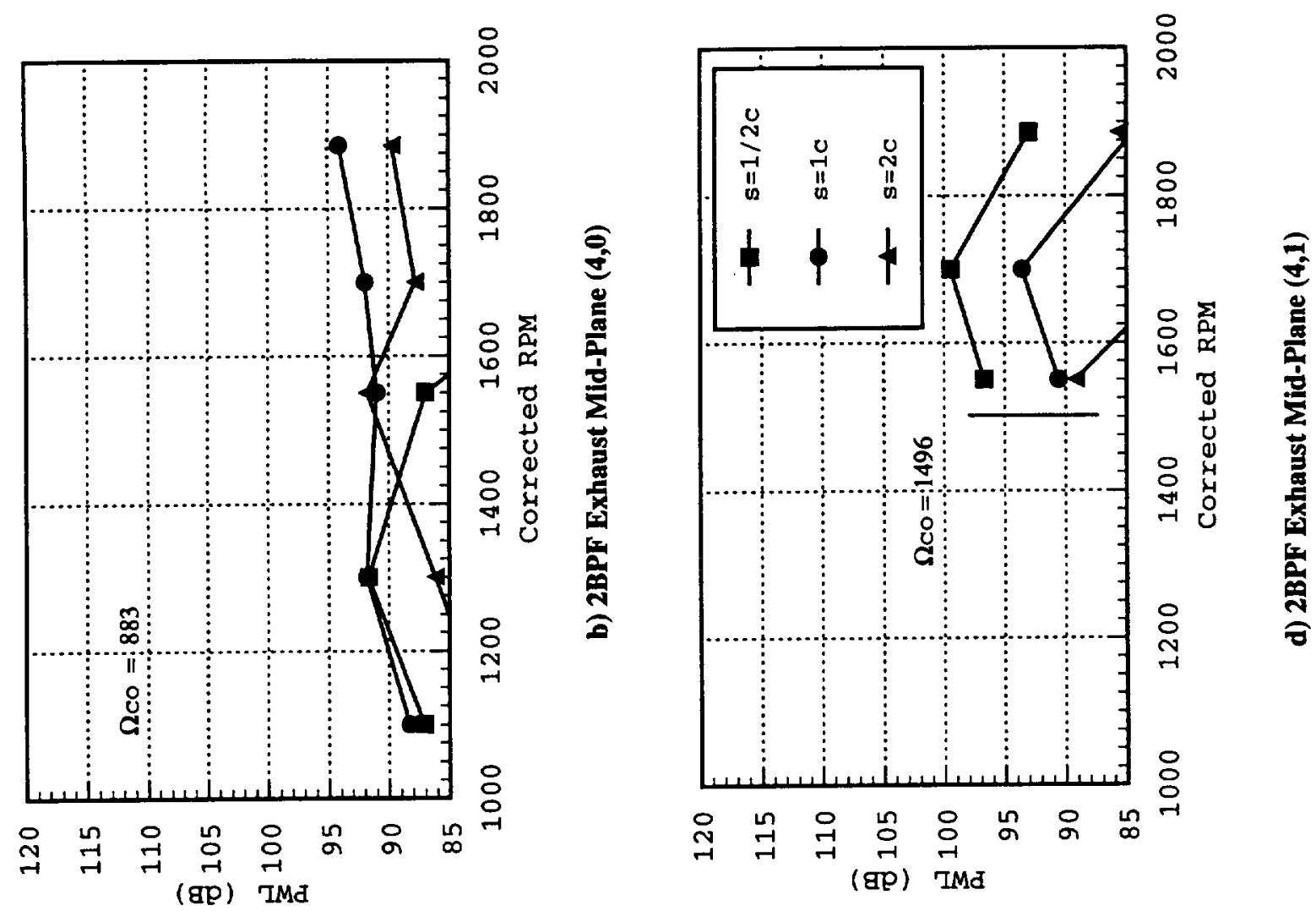

尊
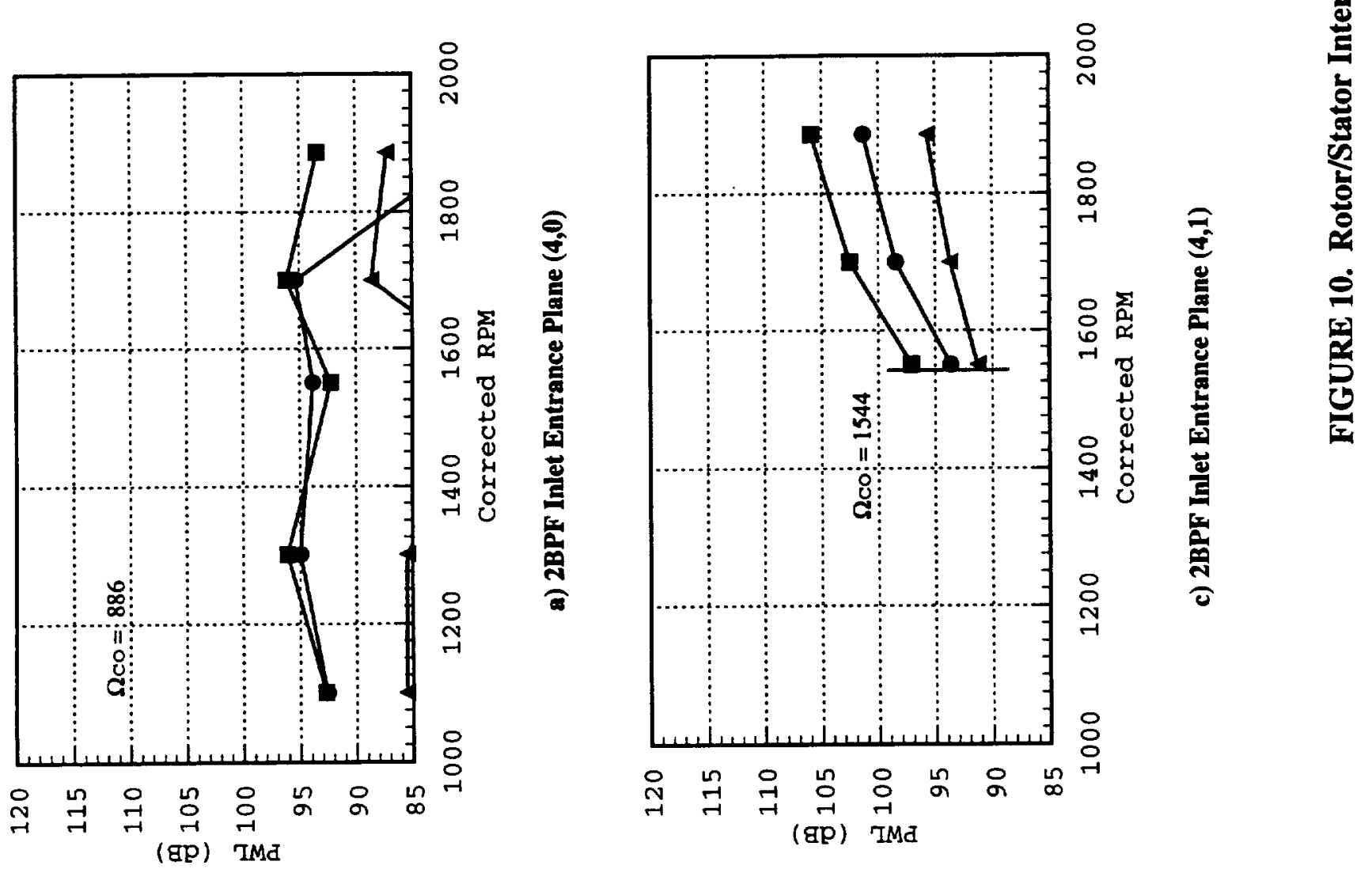


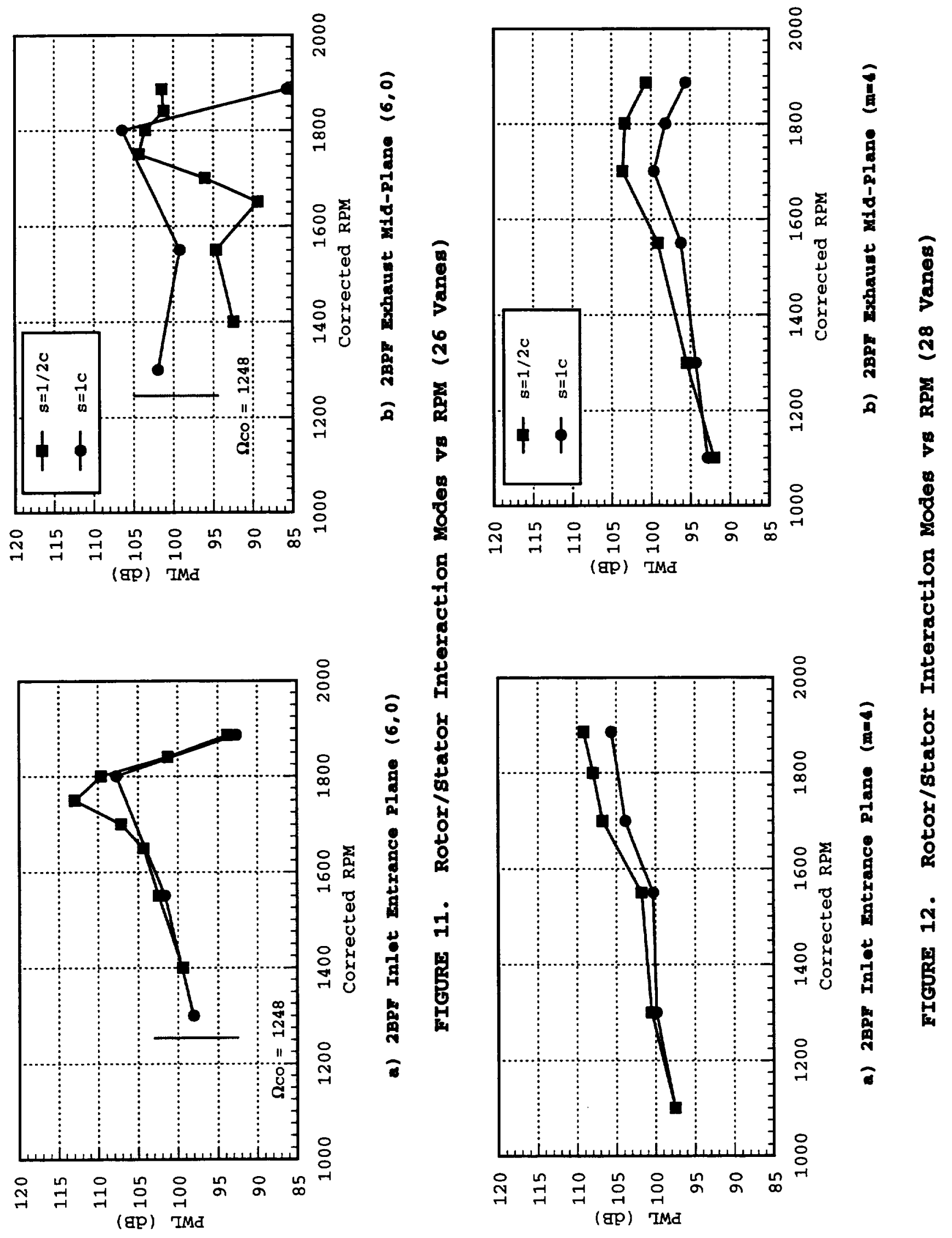



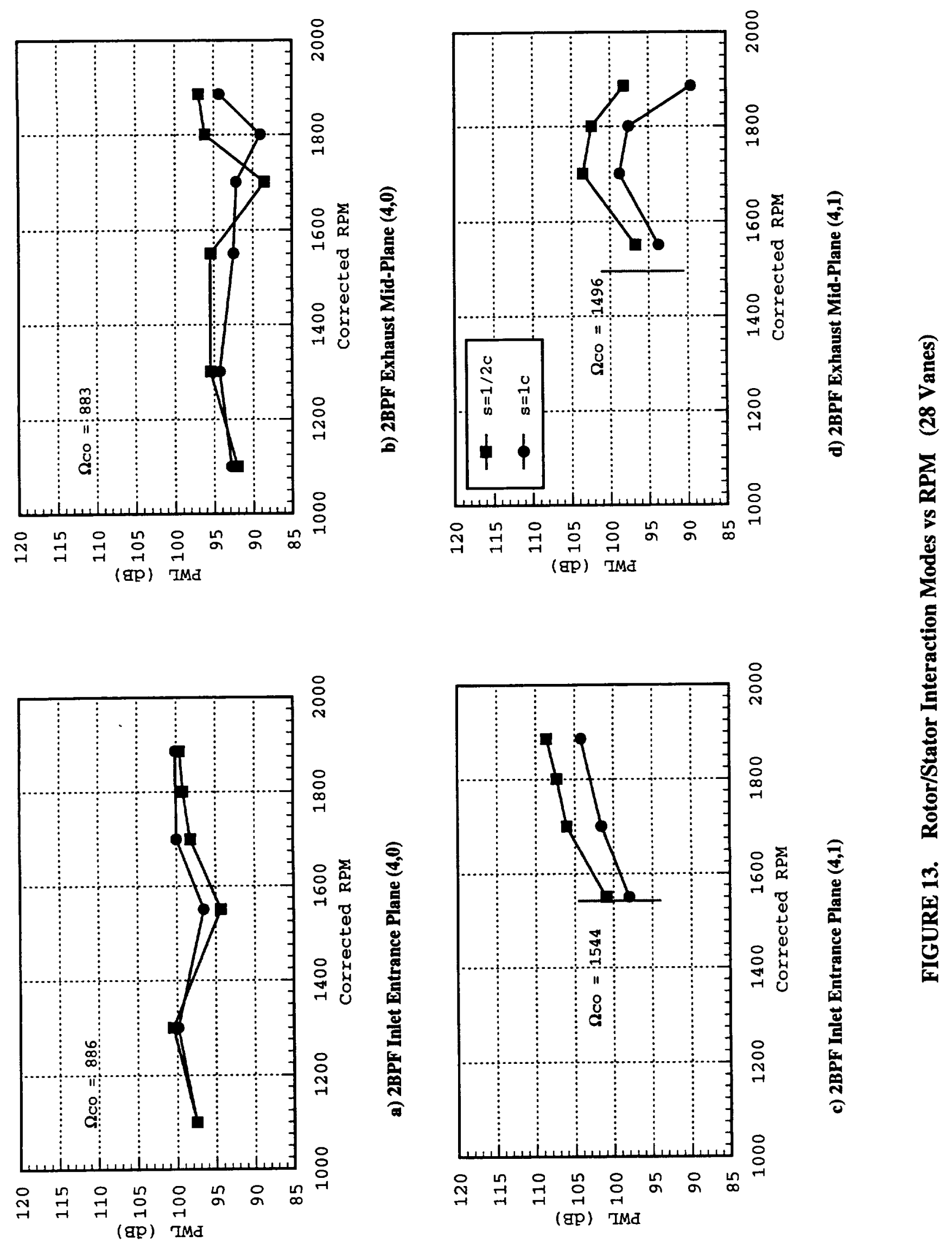

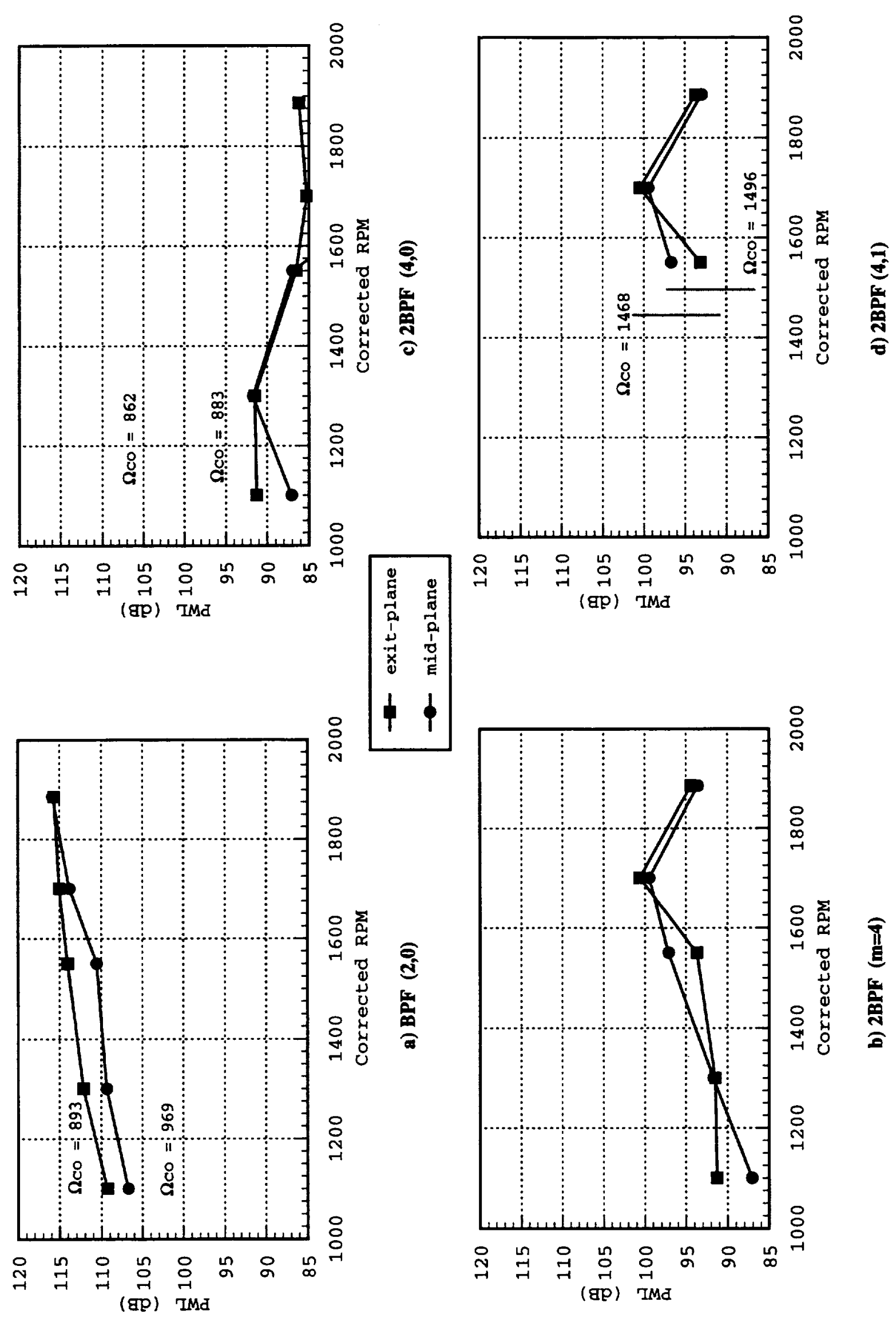

包

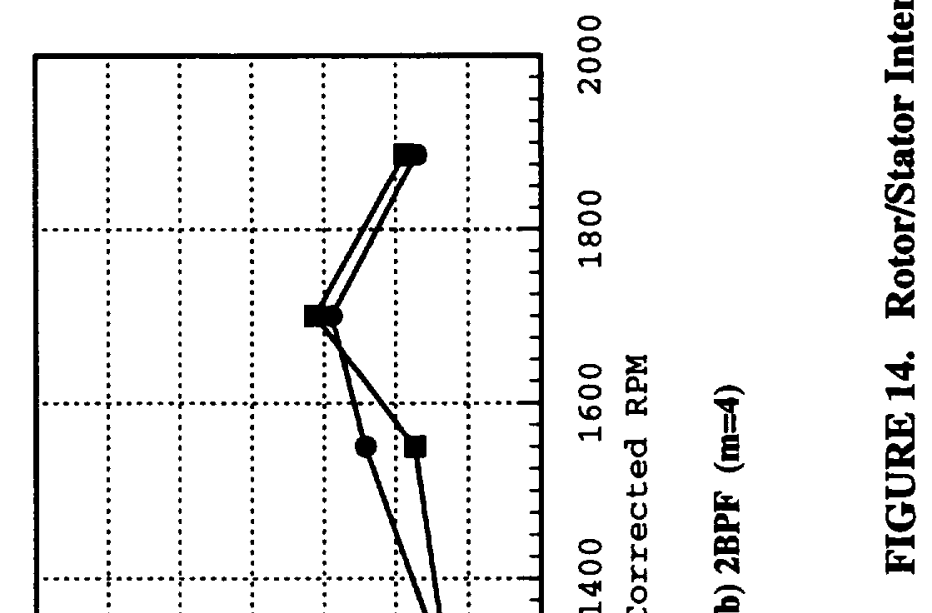




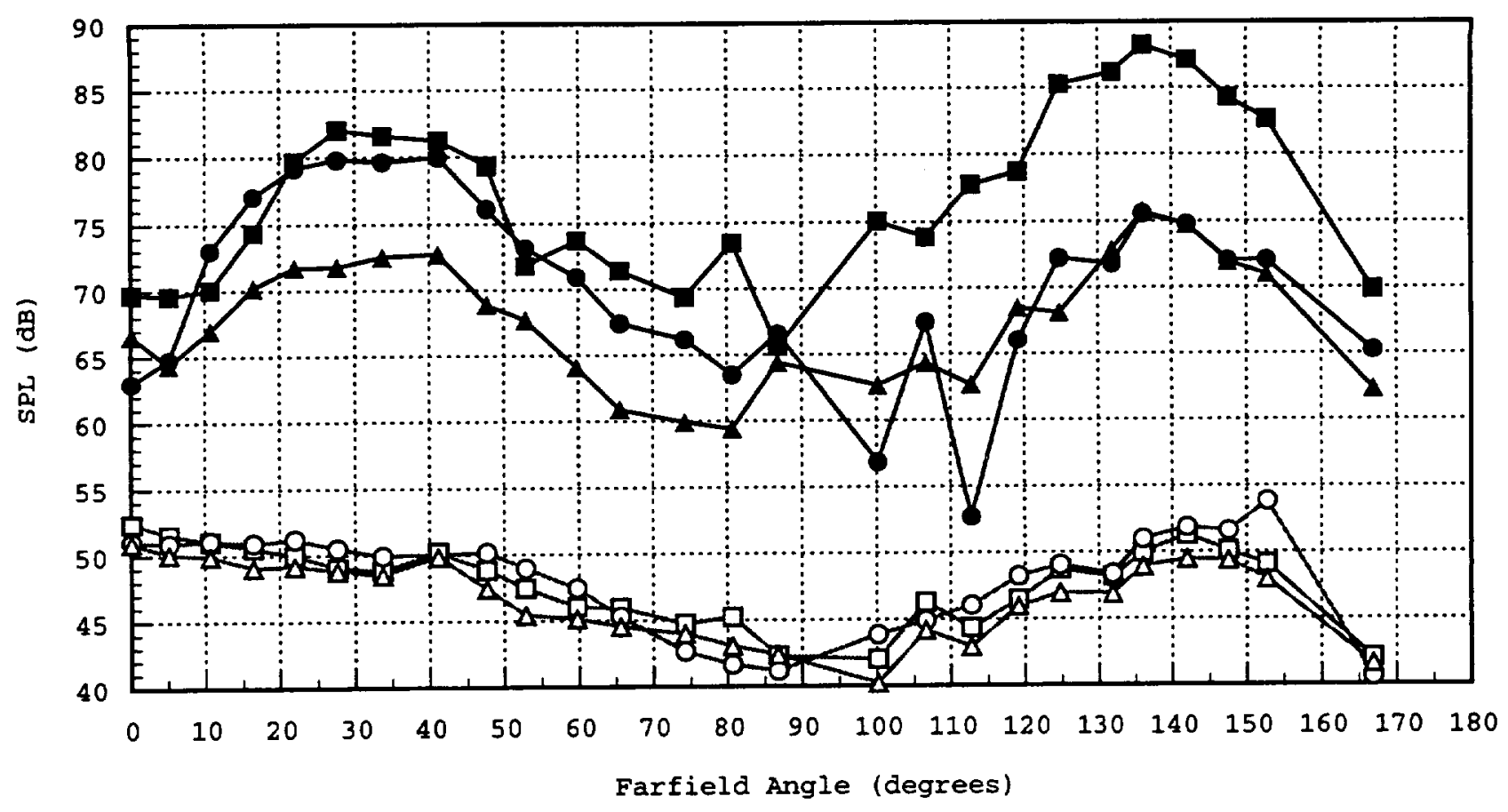

a) BPF

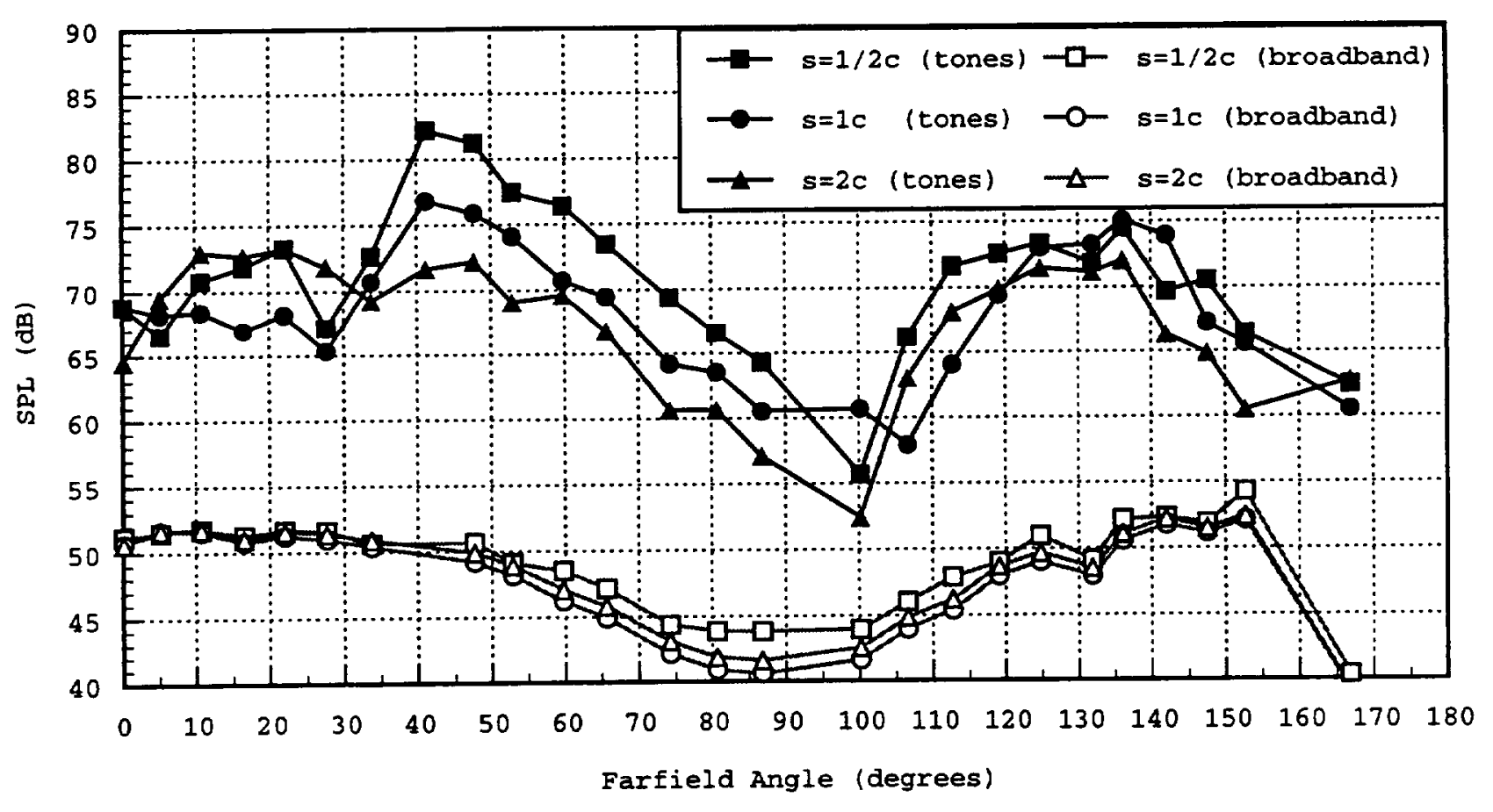

b) $2 \mathrm{BPF}$

FIGURE 15. Farfield SPLs (14 Vanes $* \Omega c=1886)$ 


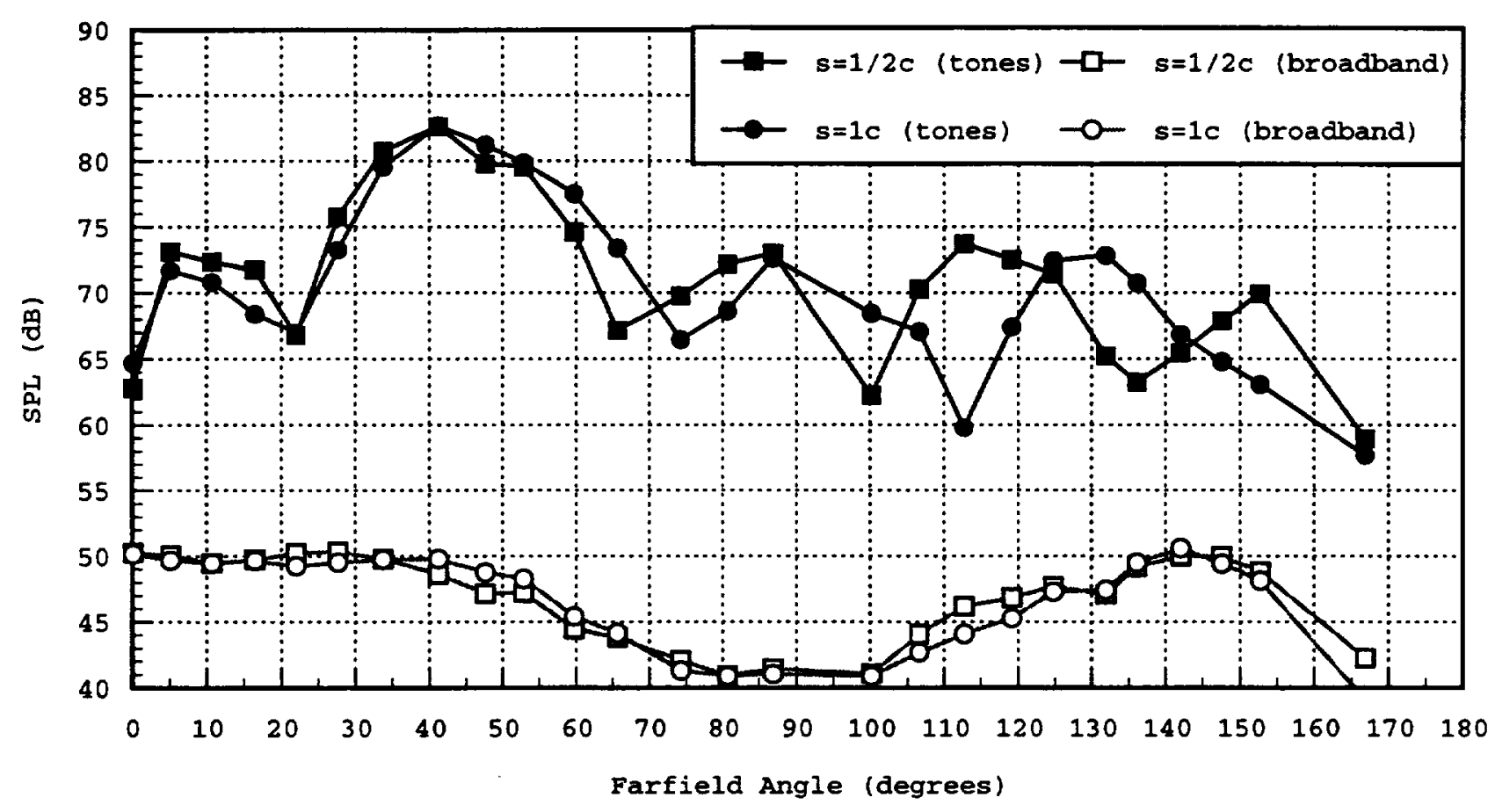

FIGURE 16. Farfield SPLs (26 Vanes $* \Omega c=1750 * 2 B P F)$

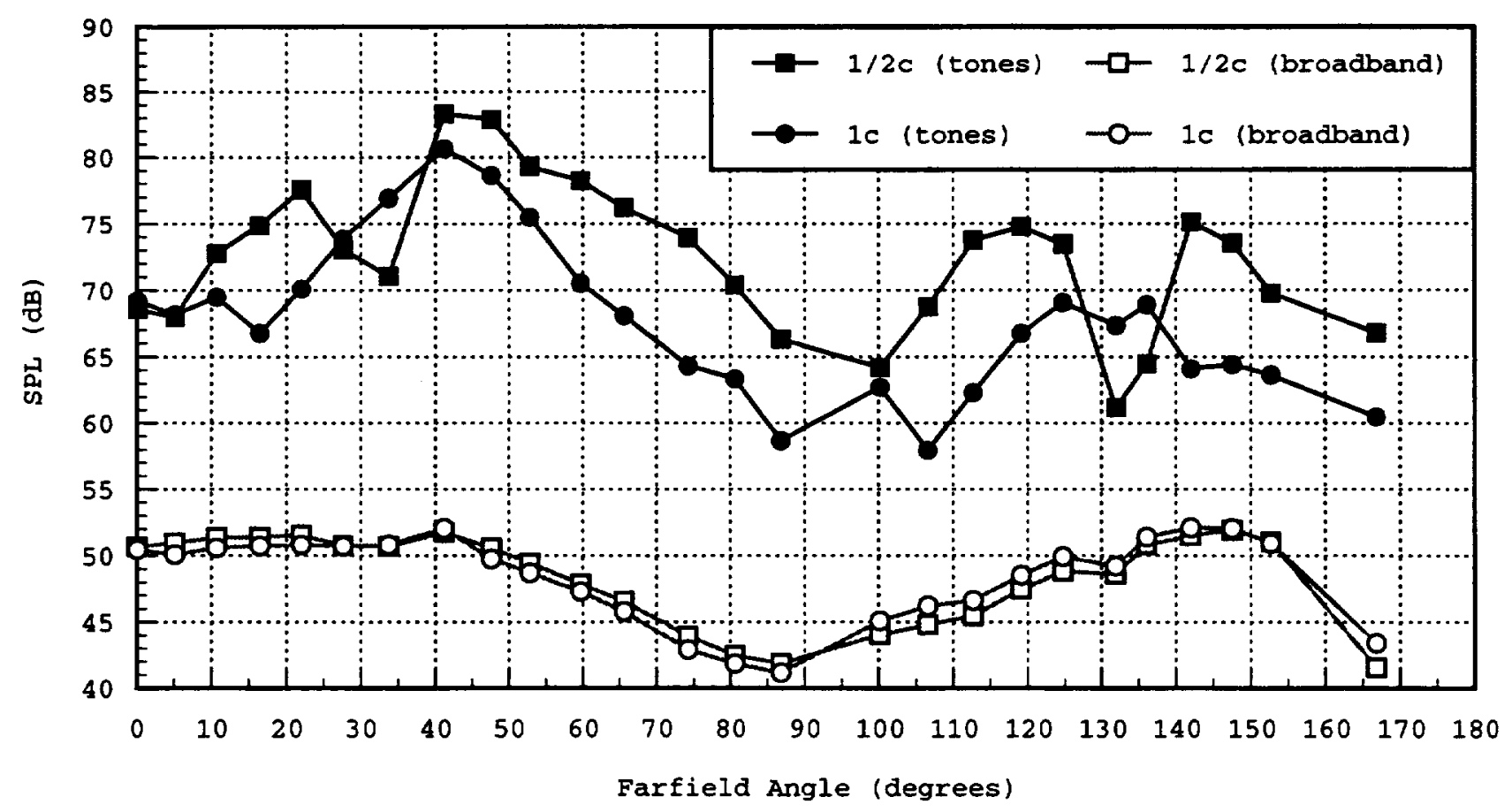

FIGURE 17. Farfield SPLS (28 Vanes * $\Omega c=1886 * 2 \mathrm{BPF}$ ) 


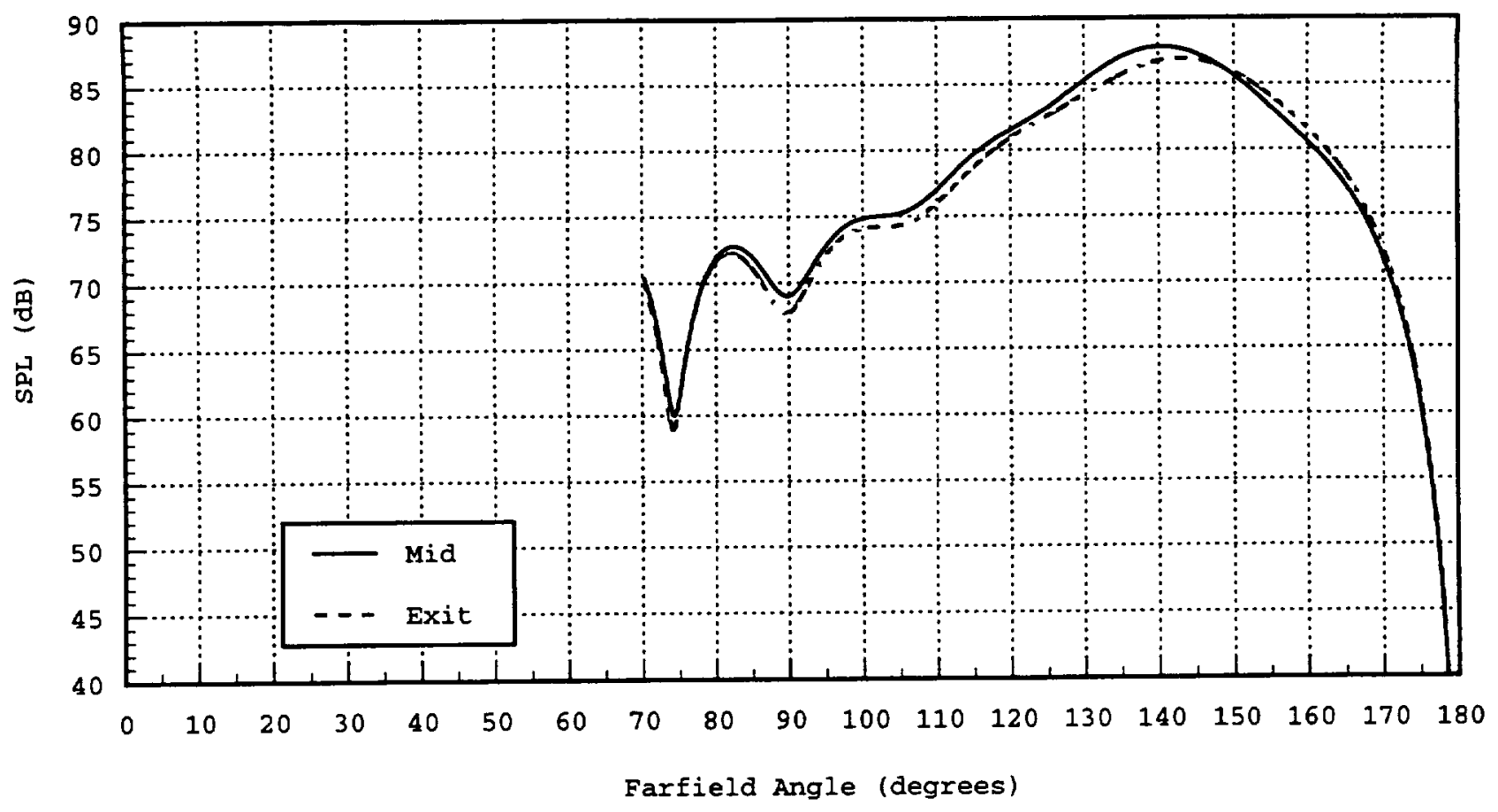

FIGURE 18. Farfield SPLs (14 Vanes @ $1 / 2 c * \Omega c=1886 *$ BPF)

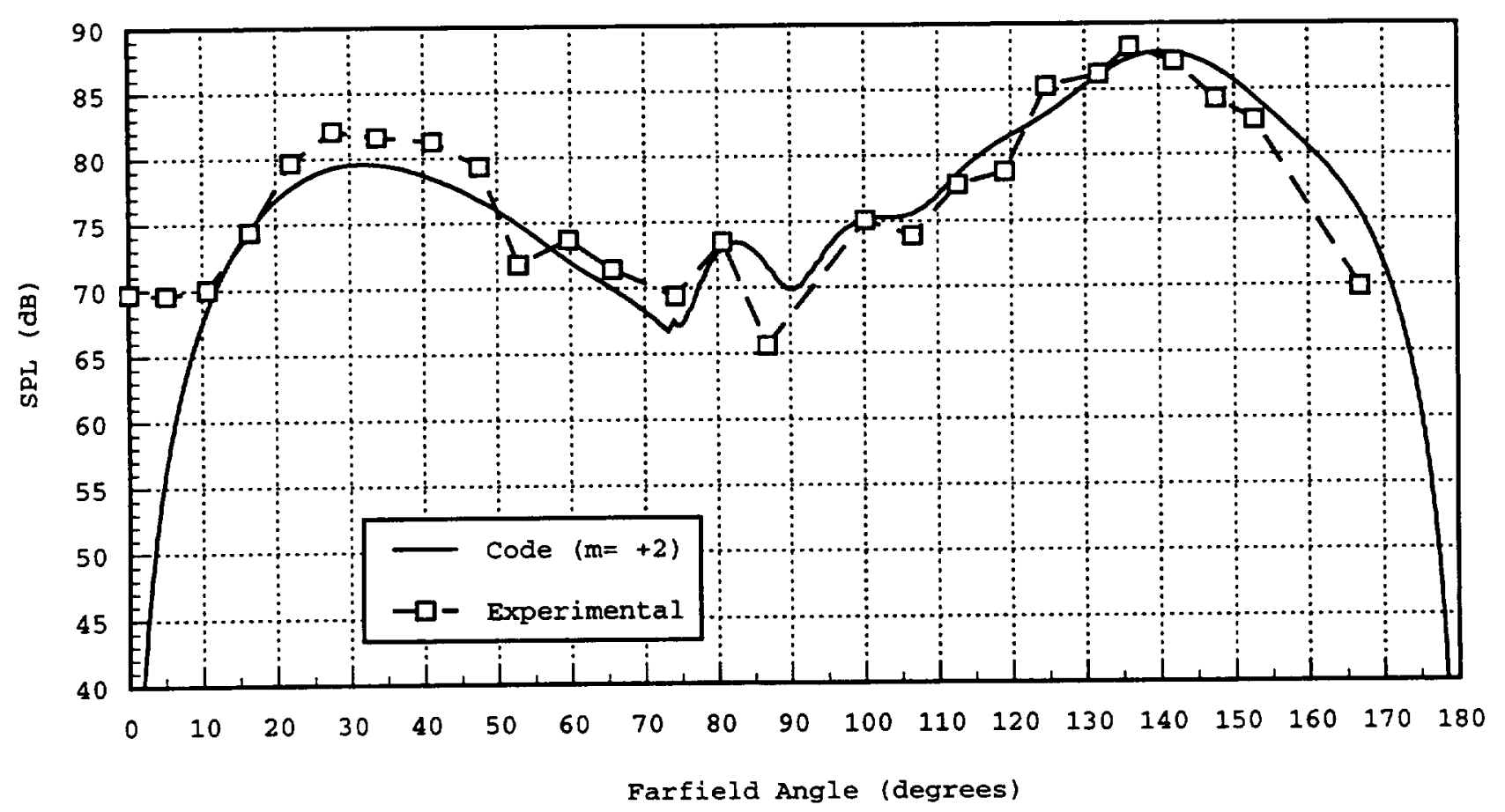

FIGURE 19. Farfield SPLs (14 Vanes @ $1 / 2 c * \Omega c=1886 *$ BPF) 


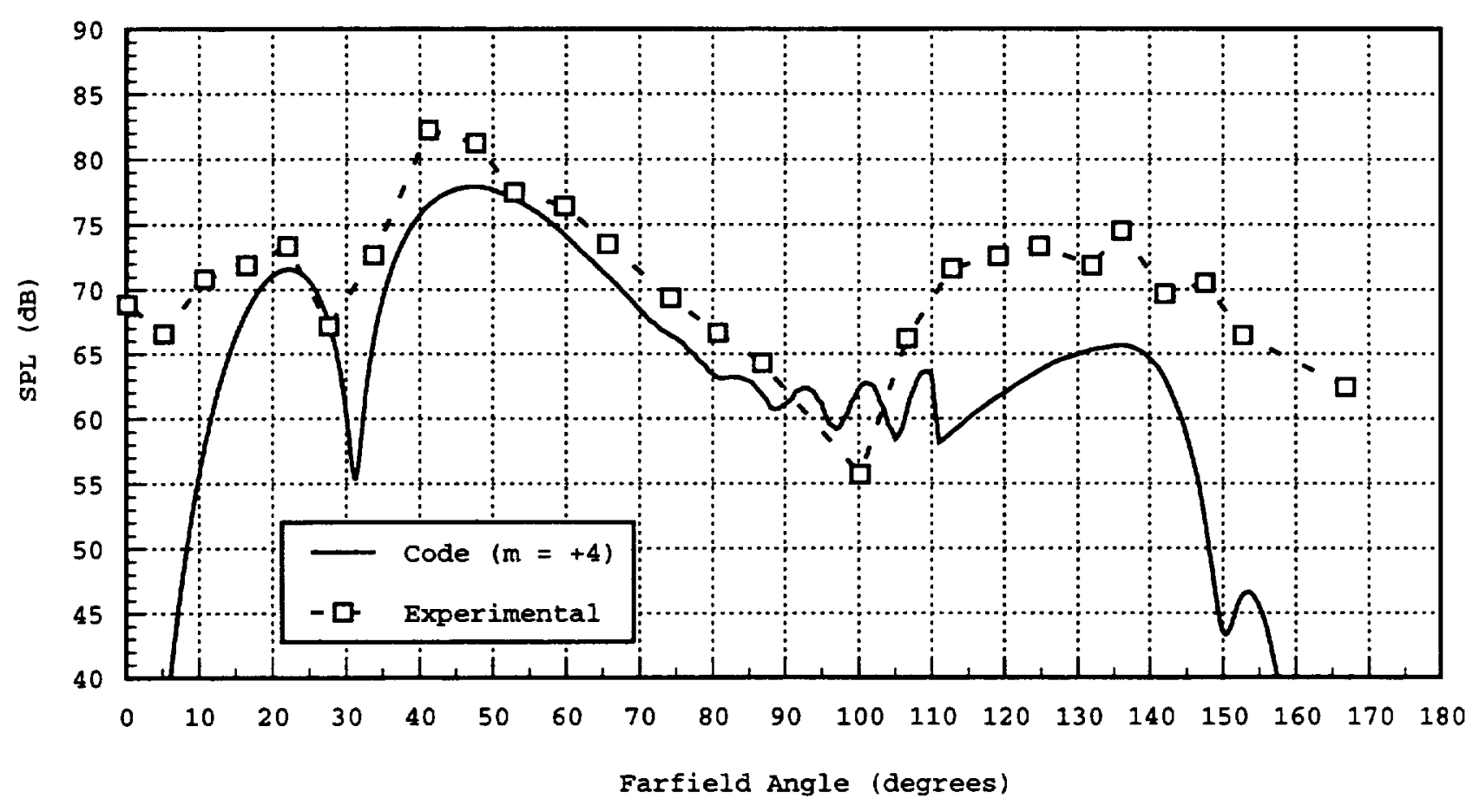

a) Single Mode

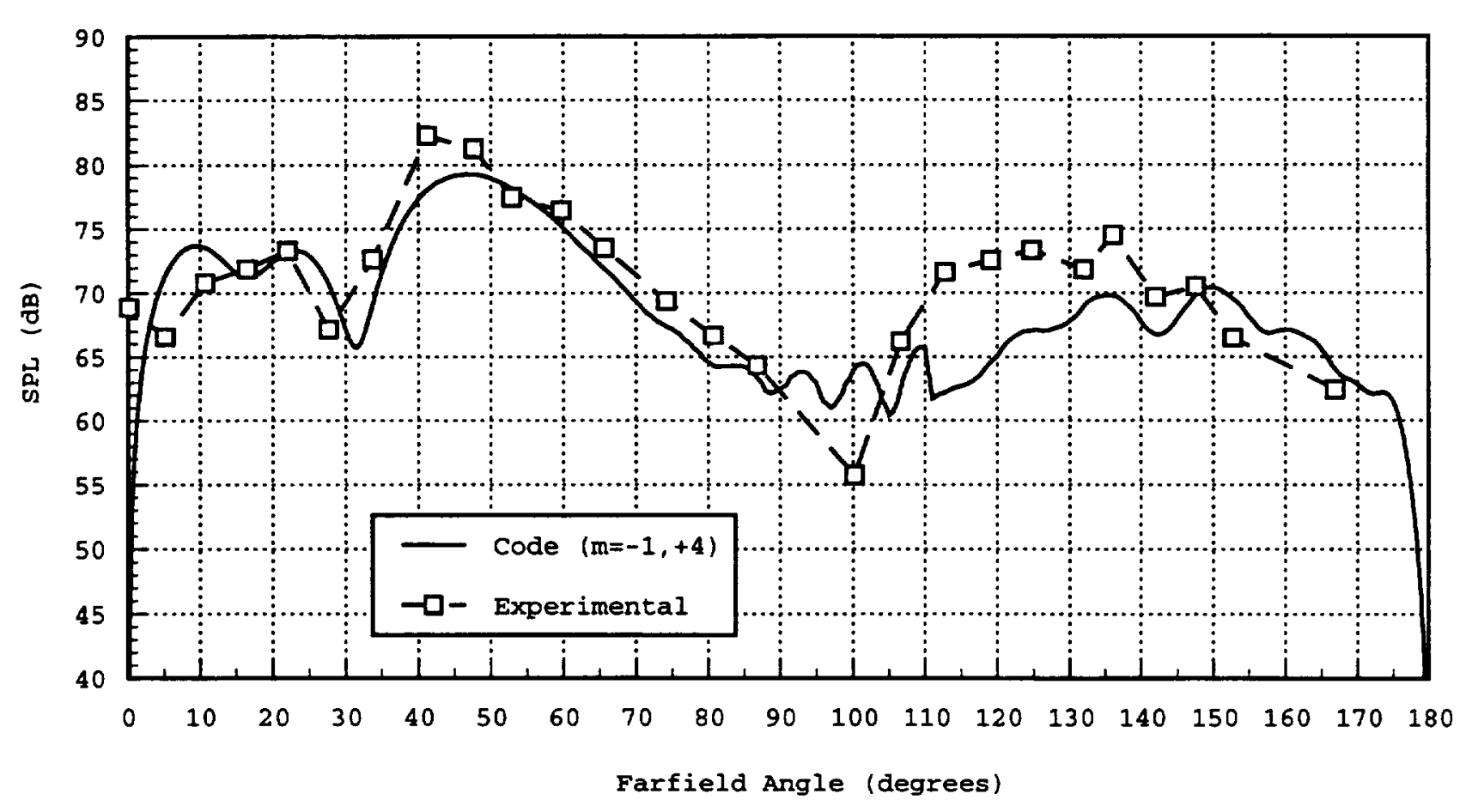

b) Multiple Modes

FIGURE 20. Farfield SPLs (14 Vanes @ $1 / 2 c * \Omega c=1886 * 2 B P F)$ 


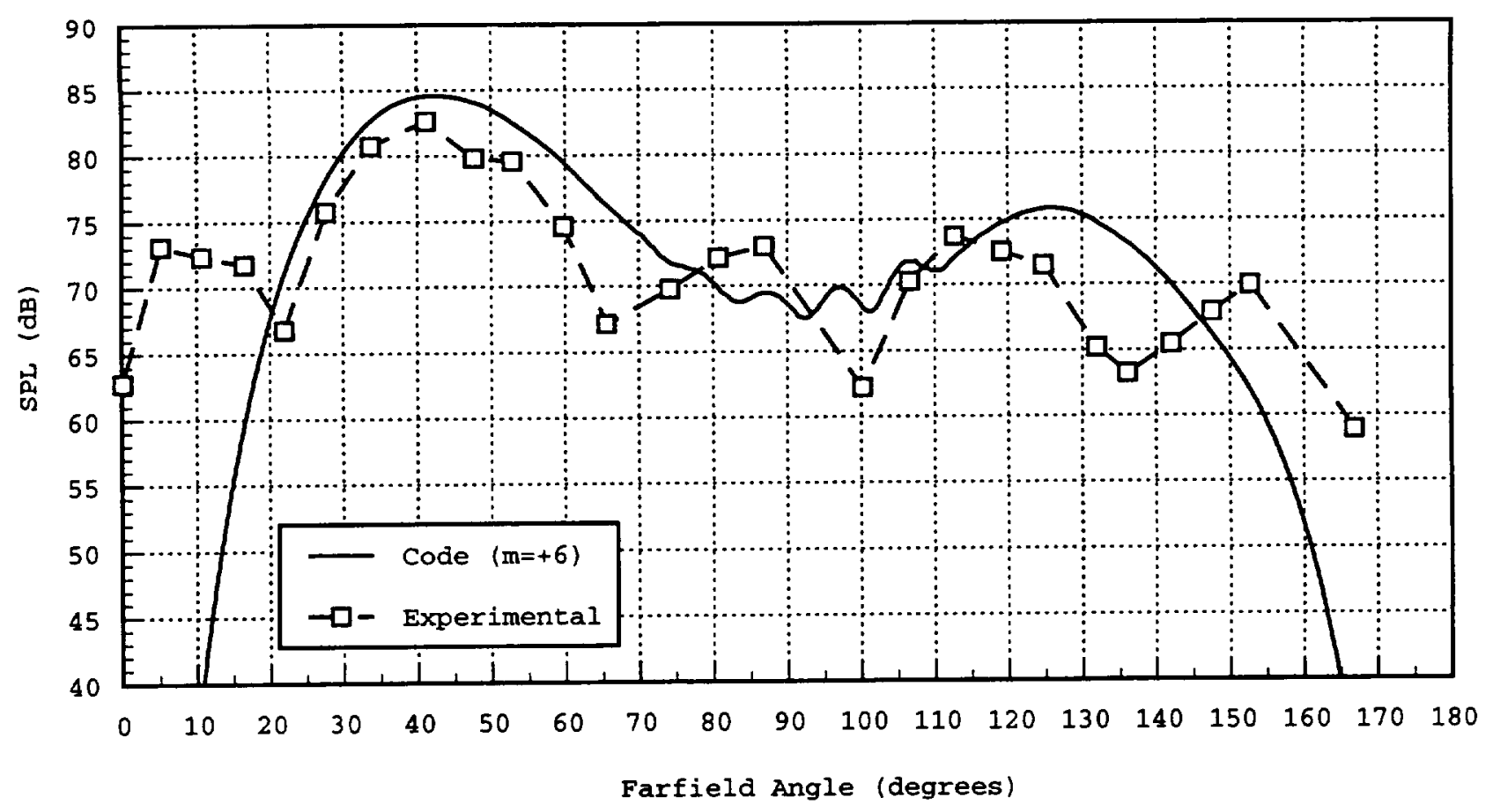

FIGURE 21. Farfield SPLs (26 Vanes @ $1 / 2 c * \Omega c=1750 * 2 B P F)$

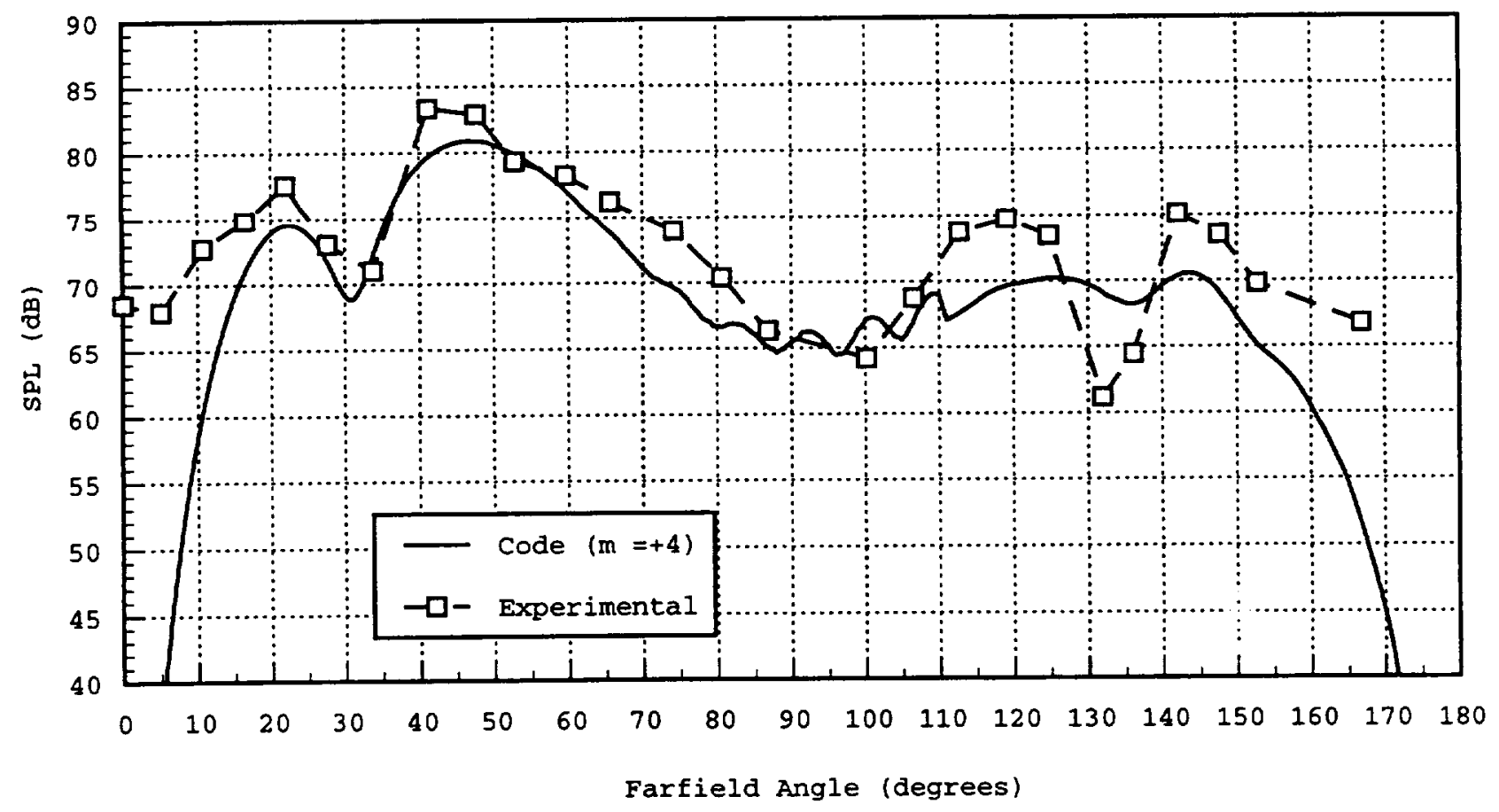

FIGURE 22. Farfield SPLs (28 Vanes @ 1/2c * $\Omega c=1886 * 2 B P F)$ 


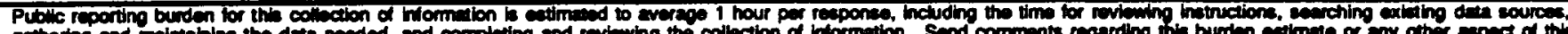

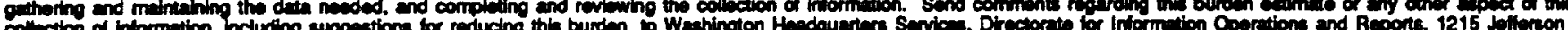

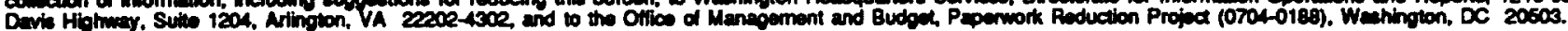

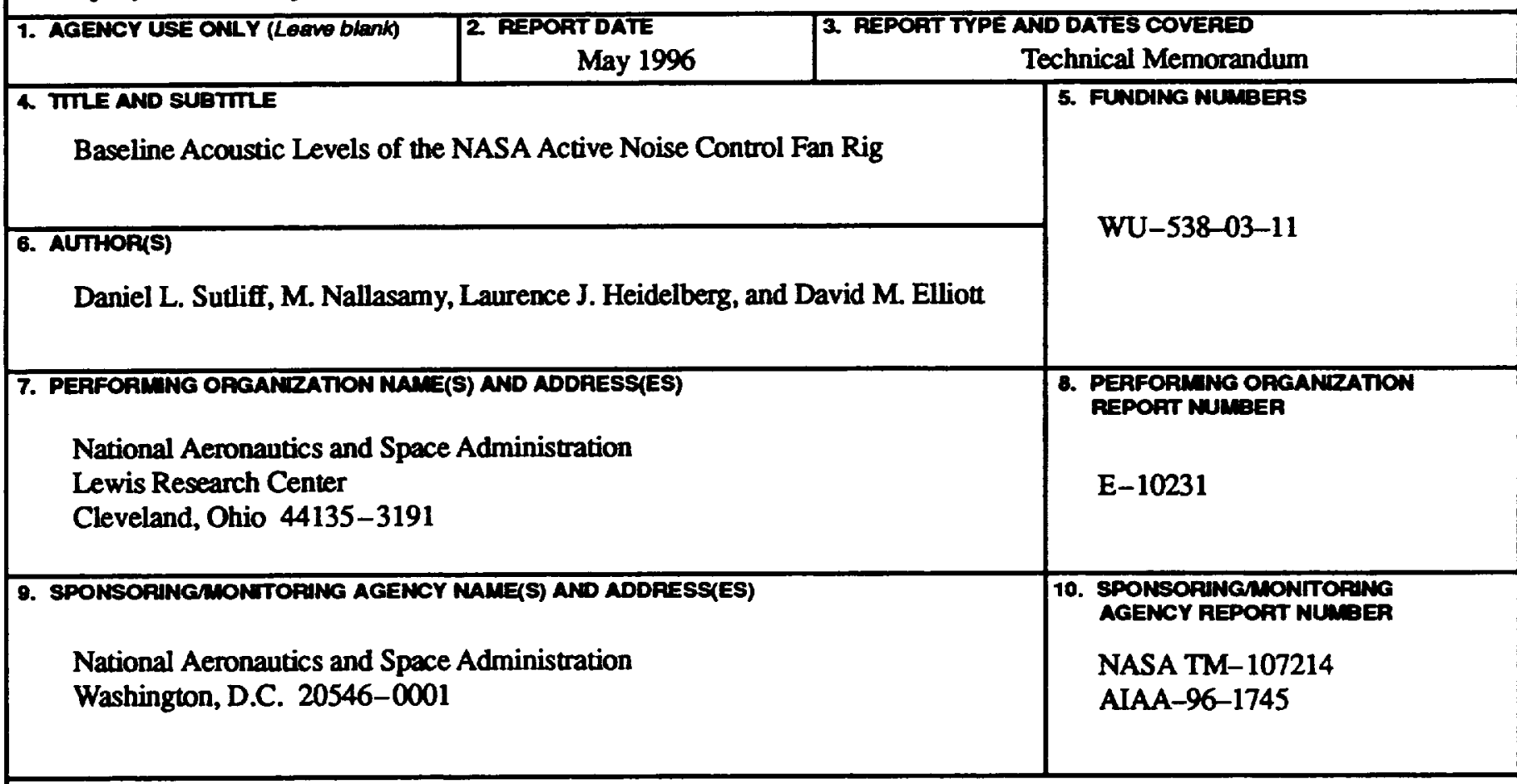

\section{SUPPLEMENTARY NOTES}

Prepered for the Second Aeroeconstics Conference cosponsored by the Americen Institute of Aeronautics and Astronautics and Confederation of European Societies, Sture College, Pennsylvania, May 6-8, 1996. Damiel L. Sulliff, National Research Council-NASA Research Associate at Lewis Research Center, Leurence J. Heidelberg and Devid M. Ellion, NASA Lewis Research Center, M. Nallasumy, NYMA, Inc., 2001 Aerospece Parkway, Brook Park, Ohio 44142 (work funded by NASA Contract NAS3-27180). Responsible person, Daniel L Suliff, organization code 2770, (210) 433-6290.

12. DISTRIBUTIONAVALABLITY STATEIENT

12b. DISTPABUTION CODE

Unclassified - Unlimited

Subject Categories 07 and 71

This publication is available from the NASA Center for AeroSpace Information, (301) 621-0390.

13. ABSTRACT (Reximem 200 words)

Extensive measurements of the spinning acoustic mode structure in the NASA 48" Active Noise Control Fan (ANCF) test rig have been taken. A continuously rotating microphone rake system with a least-squares data reduction technique was employed to measure these modes in the inlet and exhaust. Farfield directivity pattems in an anechoic environment were also measured at matched corrected rotor speeds. Several vane counts and spacings were tested over a range of rotor speeds. The Eversman finite element radiation code was run with the measured in-duct modes as input and the computed farfield results were compared to the experimentally measured directivity pattern. The experimental data show that inlet spinning mode measurements can be made very accurately. Exhaust mode measurements may have wake interference, but the least-squares reduction does a good job of rejecting the nonacoustic pressure. The Eversman radiation code accurately extrapolates the farfield levels and directivity pattern when all in-duct modes are included.

14. SUBJECT TERMS

Fan noise; Noise reduction; Acoustic attenuation; Acoustic ducts; Ducted fans

15. MUMBER OF PAGES

\begin{tabular}{|c|c|c|c|}
\hline $\begin{array}{c}\text { 17. SECUATY CLASSIFICATION } \\
\text { OF REPORT } \\
\text { Unclassified }\end{array}$ & $\begin{array}{c}\text { 18. SECURTY CLASSIFICATION } \\
\text { OF THIS PAGE } \\
\text { Unclassified }\end{array}$ & $\begin{array}{c}\text { 19. SECURTY CUASSIFICATLON } \\
\text { OF AQSTRMCT } \\
\text { Unclassified }\end{array}$
\end{tabular}




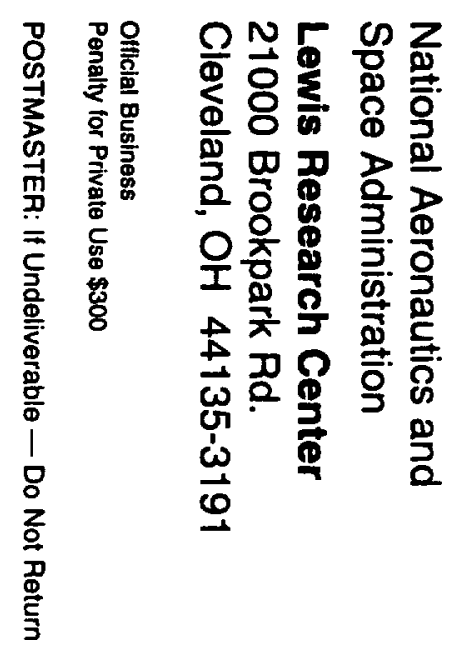

